\title{
EVALUATION OF PHYSICO-CHEMICAL PRETREATMENT METHODS FOR LANDFILL LEACHATE PRIOR TO SEWER DISCHARGE
}

\author{
by \\ Mario Poveda \\ A Thesis submitted to the Faculty of Graduate Studies of \\ The University of Manitoba \\ in partial fulfilment of the requirements of the degree of
}

MASTER OF SCIENCE

Department of Civil Engineering

University of Manitoba

Winnipeg, Manitoba R3T 5V6

Canada

March, 2015

Copyright $@ 2015$ by Mario Poveda 


\section{ACKNOWLEDGMENTS}

I would like to thank Dr. Q. Yuan and Dr. J. Oleszkiewicz for their constant support and invaluable advice during the past two years. Your guidance and friendship surpassed the academic and made me a better professional. Special thanks to Dr. S. Lozecznik for his technical assistance and words of encouragement; but above all, for his friendship. To Mr. V. Wei, for his kind disposition to always answer my every question.

I would also like to thank Mr. Chris Kozak and other collaborators at the Brady Road Resource Management Facility for always lending a hand. The work all of you do in the field is remarkable and keeps the place going.

To my fellow students, Ms. M. Lashkarizadeh, Mr. D. Kruk, Mr. P. Jabari, Ms. L. Winnning, Mr. F. Zurzolo, Mr. T. Devlin and Mr. A. di Biase, we shared the day to day defeats and victories. Without any of you, this experience would have not been the same.

Thanks to my family, my parents Alvaro and Georgina, my brother Jose Pablo and my sister Maria for your constant faith in me and my work. You have shaped me into the man I am today. Finally, I want to thank my wife, Nelcy Zuniga. You were always the reason for doing this and then became the force that allowed me to finish it.

This research was financially supported by the Natural Sciences and Engineering Research Council of Canada (NSERC), KGS Group and collaboration from the City of Winnipeg. 


\section{Contents}

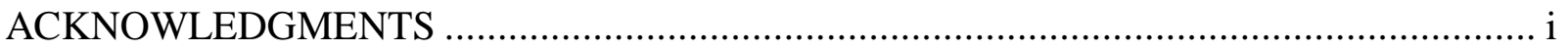

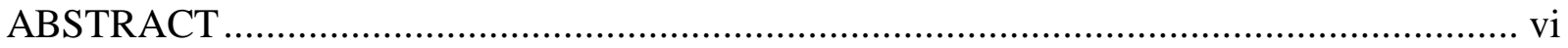

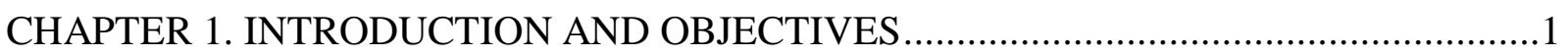

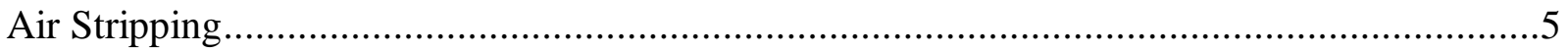

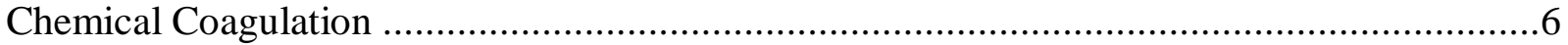

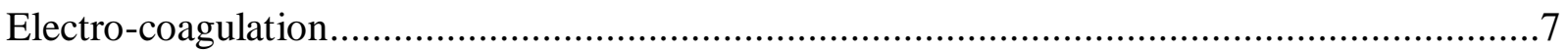

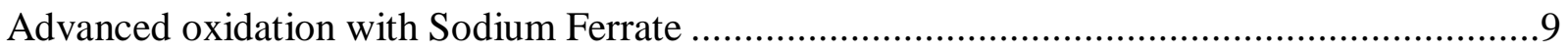

Additional Measurements for Efficiency Comparison ........................................................10

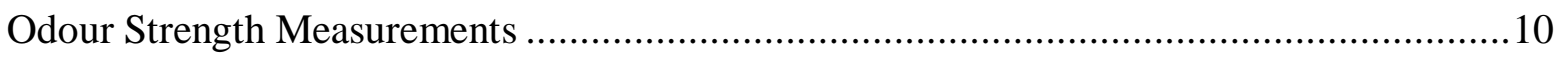

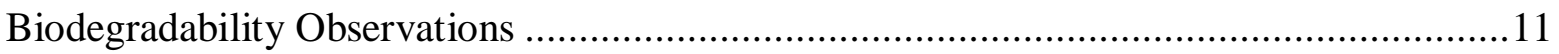

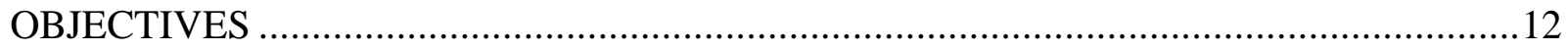

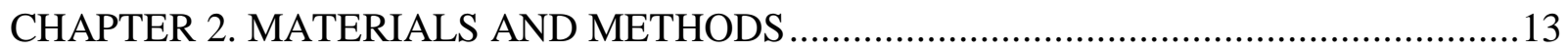

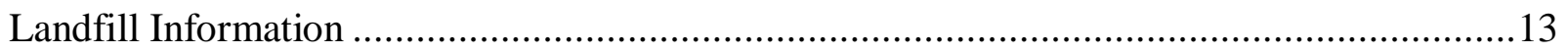

Sampling Procedure

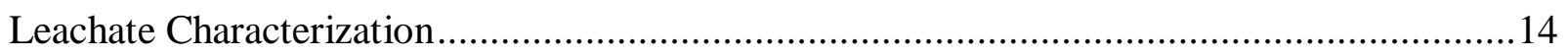

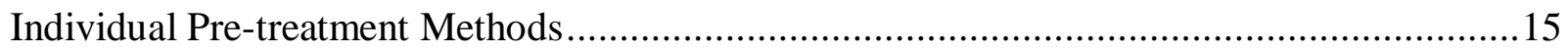

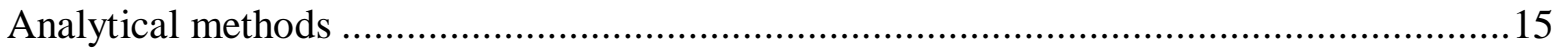

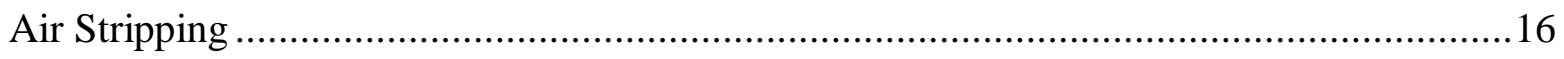

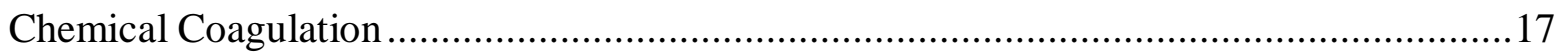

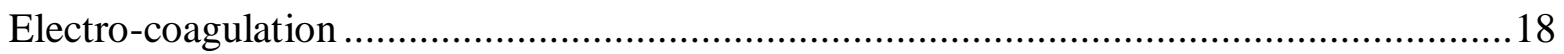

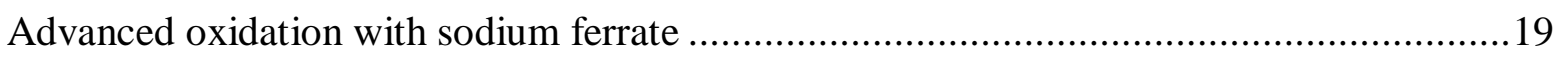

Additional Measurements for Efficiency Comparison .....................................................20

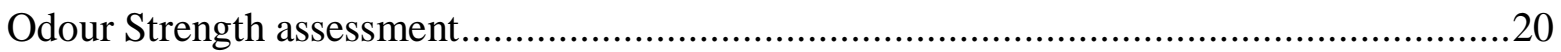

Evaluation of Pre-treatment Combination Efficiency ……….............................................21

Pre-Treatment Effect on Nitrification Kinetics ...............................................................22

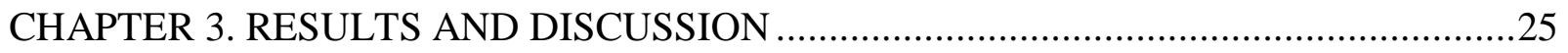

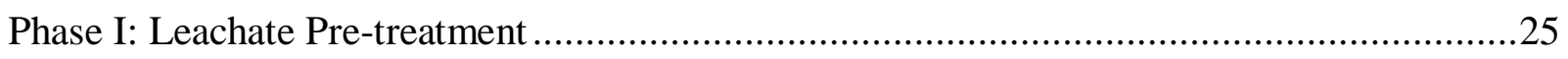

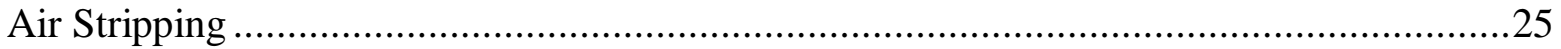

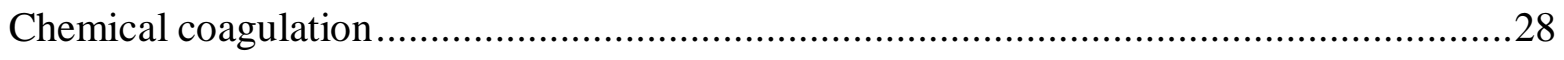

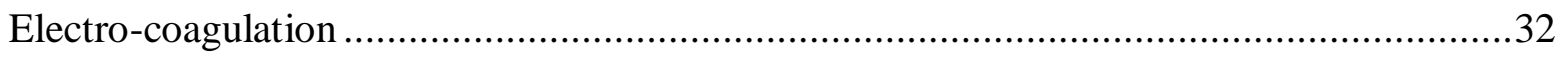


Advanced Oxidation with Sodium ferrate............................................................... 35

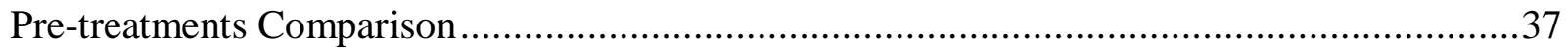

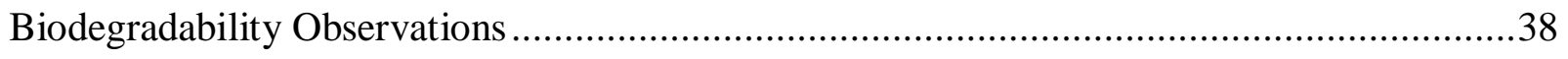

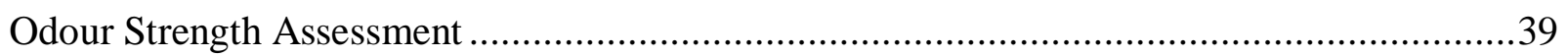

Combination of Selected Pre-treatments .......................................................................39

Phase II: Effect of Pre-treated Leachate on Biological System ....................................41

Stage 1: Short Term Test (shock load) ............................................................41

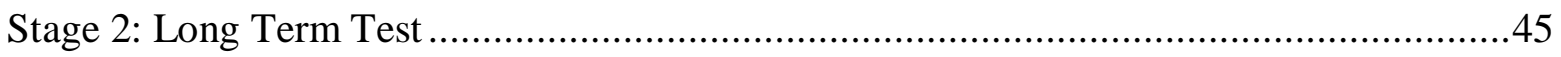

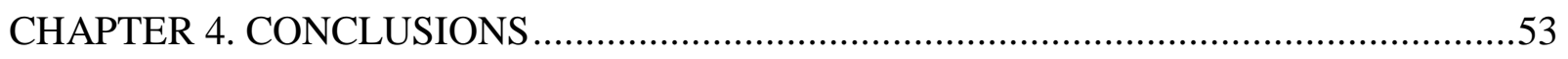

CHAPTER 5. ENGINEERING SIGNIFICANCE ......................................................58

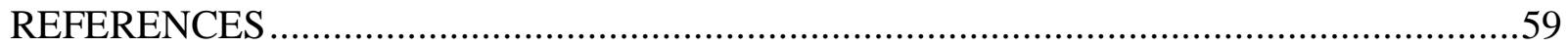

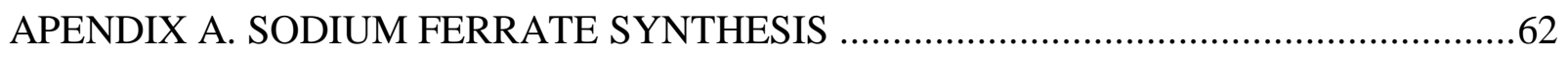

APENDIX B. ODOUR MEASUREMENT PROCEDURE .......................................64 


\section{Figures}

Figure 1. Diagram for an electro-coagulation cell. Modified from Mollah et al. (2004).............8

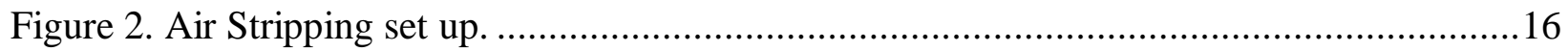

Figure 3. Set up for chemical coagulation................................................................. 17

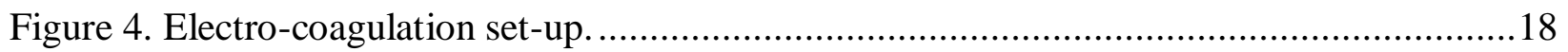

Figure 5. Set up for sodium ferrate solution. ................................................................ 19

Figure 6. Nasal Ranger® Field Olfactometer component diagram ........................................20

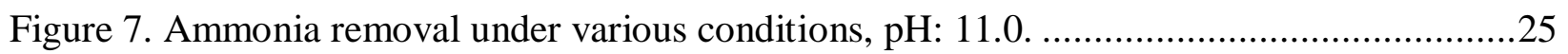

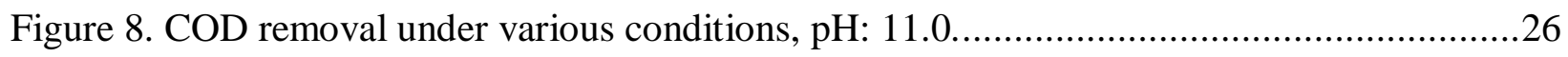

Figure 9. Excessive foaming during first minutes of air stripping. ..................................2

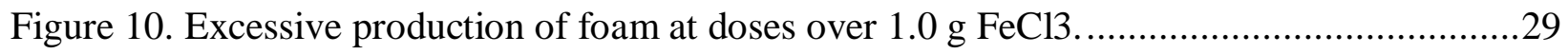

Figure 11. COD and ammonia removal results for chemical coagulation pre-treatment at $\mathrm{pH}$ 5.0.

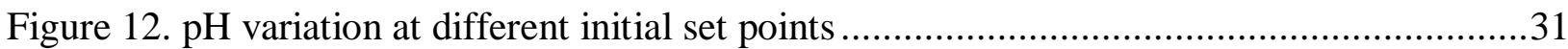

Figure 13. Results for electro-coagulation pre-treatment. Contact time: $30 \mathrm{~min}, \ldots \ldots \ldots \ldots \ldots \ldots \ldots . . . . . .32$

Figure 14. Scum deposits formed on the metal electrodes..................................................34

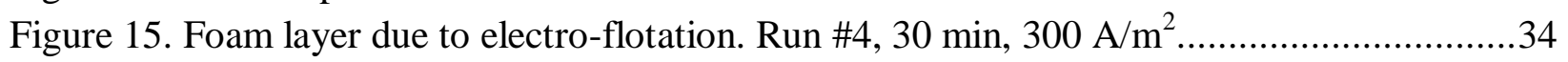

Figure 16. $\mathrm{pH}$ values after treatment for the four initial $\mathrm{pH}$ values....................................35

Figure 17. Best results for sodium ferrate pre-treatment at $\mathrm{pH} 5.0$.......................................36

Figure 18. Impact of untreated and pre-treated leachate on ammonia degradation at different

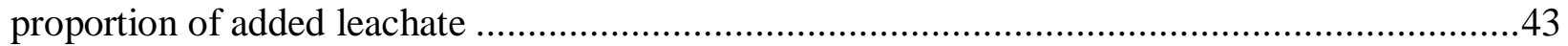

Figure 19. Impact of untreated and pre-treated leachate on soluble COD degradation at different

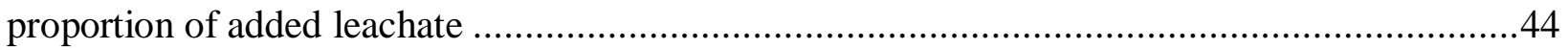

Figure 20. Long term biological treatment test set up. ..................................................45

Figure 21. Total COD feed and effluent for Control, Treated and Untreated reactors during

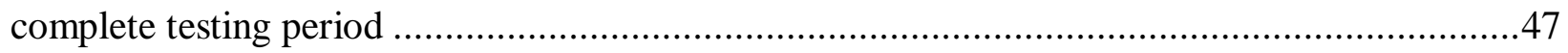

Figure 22. Soluble COD degradation during one SBR cycle. ...............................................48

Figure 23. Ammonia feed and effluent for Control, Treated and Untreated reactors.................49

Figure 24. Ammonia degradation during one SBR cycle. ...........................................50

Figure 25. NOx degradation during one SBR cycle. ................................................51

Figure 26. Phosphorus degradation during one SBR cycle...............................................52 


\section{Tables}

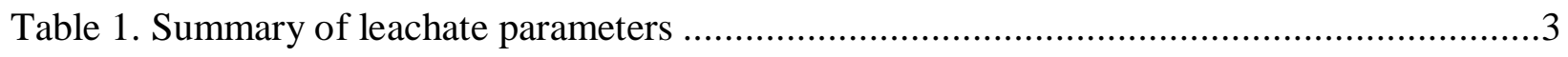

Table 2. Characteristics of tested leachate ....................................................................... 14

Table 3. Optimum conditions for the evaluated treatment options ........................................37

Table 4. Removal efficiency results for the analyzed pre-treatment options ............................38

Table 5. BOD/COD ratios for untreated and treated leachate ............................................38

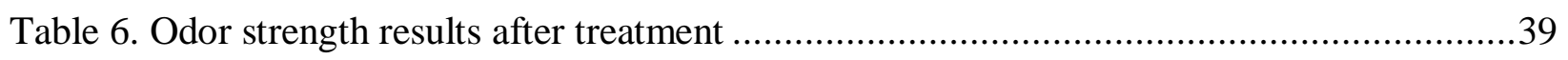

Table 7. Removal efficiency results for Combination 1 ......................................................40

Table 8. Removal efficiency results for Combination 2 ................................................40 


\section{ABSTRACT}

The City of Winnipeg, MB currently hauls by truck the leachate from the landfill, to be cotreated with the municipal wastewater at a wastewater treatment plant. Pre-treating the leachate with physico-chemical methods would allow for direct discharge to the sewer system, avoiding transportation. The goal of this research is to evaluate the effectiveness of different pre-treatment options as well as their impact on a biological nutrient removal system.

In Phase I, the four pre-treatment options evaluated were air stripping, chemical coagulation, electro-coagulation and advanced oxidation with sodium ferrate. Chemical coagulation and air stripping reported the best COD and ammonia removal rates, respectively.

Phase II evaluated the effectiveness of the selected pre-treatment methods in the response of a biological treatment system. The pre-treatment was successful in allowing complete nitrification by lowering the influent ammonia concentration. However, if the ratio of leachate to wastewater is low enough; pre-treatment may not be needed as the dilution lowers the impact of the leachate's higher concentrations. 


\section{CHAPTER 1. INTRODUCTION AND OBJECTIVES}

Landfill leachate is produced by the seeping of liquids through landfilled waste. Rain water or melted snow percolating into the waste, as well as the original water content or humidity of the waste itself and the degradation and compaction of the organic fraction, all contribute to the generation of leachate (Kjeldsen et al., 2002; Kurniawan et al., 2006).

The quantity and the characteristics of leachate produced are site specific and closely related to the age of the disposal cell. Different stabilization stages have been determined to be predominant after the waste is disposed and covered, starting with an aerobic acidic phase. During the initial days, the oxygen trapped in the waste is consumed and $\mathrm{CO}_{2}$ is produced as the main by-product. Leachate produced during this stage is mostly due to the compaction process releasing moisture in the waste.

Then a prolonged anaerobic phase begins were acidogenic and methanogenic decomposition takes place (Kurniawan et al., 2006). The biodegradable fraction of the waste is hydrolyzed by fermentative bacteria that produce extracellular enzymes to help break down and solubilize large compounds. During fermentation, the simple carbohydrates and amino acids are degraded by different pathways, a direct conversion into acetate (Acetogenesis), a small percentage is degraded into $\mathrm{H}_{2}$ and $\mathrm{CO}_{2}$ and a third process that produces intermediate compounds: ShortChain Fatty Acids (like butyric acid, propionic acid) and alcohols. These intermediate compounds are eventually converted into acetate, and small amounts of $\mathrm{H}_{2}$ and $\mathrm{CO}_{2}$. In the last phase, methane producing microorganisms, utilize the available substrate and convert it into the gaseous compounds, from fully reduced methane to fully oxidised carbon dioxide. At the beginning of this methanogenic phase the highest concentrations of 5 days Biochemical Oxygen 
Demand $\left(\mathrm{BOD}_{5}\right)$ and $\mathrm{COD}$ are usually found in the produced leachate. As the simpler organic compounds are degraded, BOD concentration would decrease and COD would only represent the most refractory compounds that are left behind.

The characteristics of the leachate are closely related to the conditions on the disposal site and the degradation time that has passed. In addition, the parameters that affect the leachate characteristics include

- Precipitation (rain, snow melt, etc.)

- Surface run-off (if not controlled by diversion and collection structures)

- Infiltration through the daily cover

- Evapotranspiration

- Compaction of waste

- Type of waste

- Water content of the waste

Kjeldsen et al. (2002) introduced four major groups that would represent the typical Municipal Solid Waste (MSW) Landfill leachate parameters:

- Organic matter: both biodegradable and non-biodegradable measured as $\mathrm{COD}, \mathrm{BOD}_{5}$ or Total Organic Carbon (TOC).

- Inorganic compounds: calcium, magnesium, sodium, potassium, iron, manganese, nitrogen (measured as Total Nitrogen, Total Kjeldan Nitrogen, ionized or un-ionized, etc.), chloride, sulfate and hydrogen carbonate.

- Heavy metals: cadmium, chromium, copper, lead, nickel and zinc to name some. 
- Xenobiotic organic compounds (XOC's): aromatic hydrocarbons, phenols, chlorinated aliphatics, pesticides, and plastizers.

The values presented in Table 1 are based on summary tables reported by Renou et al. (2008) and Kjeldsen et al. (2002). The mentioned tables were based on over 40 investigations related to the characterization and treatment of leachate, covering research from 1975 to 2008 . In Table 1, it is clearly shown the very high variation within each parameter of leachate.

Table 1. Summary of leachate parameters

\begin{tabular}{r|c}
\hline Parameter & $\begin{array}{c}\text { Range (Values in } \\
\text { mg/L except } \mathrm{pH})\end{array}$ \\
\hline $\mathrm{pH}(-)$ & $4.5-9.5$ \\
$\mathrm{COD}$ & $100-150,000$ \\
$\mathrm{TSS}$ & $15-5,000$ \\
$\mathrm{BOD}_{5}$ & $5-55,000$ \\
$\mathrm{TN}$ & $5-13,000$ \\
$\mathrm{NH}_{3}-\mathrm{N}$ & $10-13,000$ \\
$\mathrm{TP}$ & $0.1-23$ \\
\hline
\end{tabular}

Compared to typical municipal wastewater, the higher concentrations of these compounds would inhibit and render inoperative a traditional wastewater treatment plant, if no pre-treatment is used.

During the early stages at sites with a high percentage of biodegradable refuse, the leachate will contain a high concentration of volatile fatty acids (VFA's).Biological treatment would be a better option for this type of leachate. On the later stages, the older leachate will present higher concentrations of refractory compounds like humic substances (Kjeldsen et al., 2002; Renou et al., 2008). Physic-chemical treatment would be a better option for this type of leachate. 
There are numerous methods, such as physicochemical and biological, designed to treat wastewater with high levels of toxic contaminants. The selection of the treatment will mainly depend on the characteristics of the leachate and implementation and operation costs. Given the complex characteristics of leachate, a multi-barrier system consisting of both physical-chemical and biological treatment is usually considered the best approach (Renou et al., 2008; Wiszniowski et al., 2006). Therefore, pre-treating the leachate onsite before it is discharged into the sewer system and mixed with the municipal wastewater would be beneficial for the subsequent biological treatment at the plant.

Physico-chemical treatment is the most common practice for the removal of recalcitrant and toxic pollutants in leachate, usually coupled as a pre-treatment or polishing step with biological treatment(Kurniawan et al., 2006; Renou et al., 2008). Physico-chemical treatment may include: flotation, adsorption, precipitation, $\mathrm{pH}$ adjustment, filtration and oxidation, to name some examples. The pre-treatment options selected for this research were: air stripping, focused on the removal of dissolved volatile compounds (VC), chemical coagulation and electrocoagulation targeting the removal of colloidal particles in order the reduce the Chemical Oxygen Demand (COD) and advanced oxidation with sodium ferrate to provide a complete degradation of organic contaminants. 


\section{Air Stripping}

Air stripping is the most common procedure used to lower high concentrations of ammonia in landfill leachate, with reported ammonia removal rates of around 95\% (Cheung et al., 1997; Collivignarelli et al., 1998; Cotman and Gotvajn, 2010). It involves the mass transfer of a gas from the liquid phase to the gas phase by increasing the contact surface area available between the liquid and another gas which has a much lower concentration of the gas to be removed (Tchobanoglous et al., 2004). The procedure typically employs air to strip ammonia, odorous gases and other volatile compounds. For wastewater applications, the procedure is usually carried by using a trickling filter or stripping tower, where the wastewater is dispersed into a medium to maximize the surface contact area between the liquid and the air.

This process follows a first-order reaction relating the initial concentration of the gas to be removed from the liquid to the efficiency of the procedure, as well as parameters such as $\mathrm{pH}$, turbulence, partial pressure, temperature and reactor configuration (available surface area). Depending on the $\mathrm{pH}$ of the solution, ammonia nitrogen may be present as ionized $\left(\mathrm{NH}_{4}^{+}\right)$or unionized $\left(\mathrm{NH}_{3}\right)$ ammonia. The $\mathrm{pH}$ of the solution must be increased over the $\mathrm{pK}$ value of ammonia of 9.25 (estimated from the acid ionization constant of ammonia in water) to favor the conversion of ammonia nitrogen into ammonia gas $\left(\mathrm{NH}_{3}\right)$. Studies have demonstrated that the optimum $\mathrm{pH}$ for ammonia stripping from leachate is estimated at around 11.0 (Cheung et al., 1997; Collivignarelli et al., 1998; Guo et al., 2010; Yilmaz et al., 2010). 


\section{Chemical Coagulation}

Chemical coagulation is a simple technique widely used to remove non-biodegradable organic compounds from landfill leachate (Amokrane et al., 1997; Marañón et al., 2008; Tatsi et al., 2003). The main idea behind chemical coagulation is to destabilize colloidal particles (around 0.01 to $1 \mu \mathrm{m})$ present in wastewater. Adding a coagulant compound neutralizes the electrical charges maintaining the colloids in suspension, then by rapidly mixing the collision of particles increase their size and they can be removed by traditional methods such as settling or filtration (Tchobanoglous et al., 2004).

Aluminum sulfate (alum), ferrous sulfate and ferric chloride are among the most commonly used chemical coagulants for leachate (Renou et al., 2008; Tatsi et al., 2003). Amokrane et al. (1997) found that iron salts produced better results than aluminum salts in terms of turbidity and COD removal in leachate, a claim also supported by the literature review presented in Renou et al. (2008) where the expected COD removal rate is in the order of $50-60 \%$. A wide range of "optimum" pH values for chemical coagulation of leachate using iron salts have been proposed. This can be explained by the various hydrolysed species that $\mathrm{Fe}^{3+}$ can form depending on the sample's pH (acidic conditions: poly-nuclear cations like $\mathrm{Fe}_{2}(\mathrm{OH})_{2}{ }^{4+}$, basic conditions: anions like $\mathrm{Fe}(\mathrm{OH})_{3}$, Li et al., 2010). 


\section{Electro-coagulation}

Electro-coagulation is a procedure that involves the formation of the coagulant by electrolytic oxidation of a sacrificial electrode, the destabilization of the contaminants and the eventual aggregation into flocs and removal by precipitation and/or filtration methods. The metal ions generated from the sacrificial electrode hydrolyze into polymeric hydroxides, which are excellent coagulation agents (Mollah et al., 2001). Compared to traditional chemical coagulation, electrocoagulation advantages include less sludge production and avoiding transferring needless compounds into the leachate (Ilhan et al., 2008). Due to the numerous and sensitive parameters governing this technique (electrode material and contact area, type and amount of current, voltage, contact time) its application is not very common for the treatment of landfill leachate. High turbidity and color removal rates are reported, but COD removal rates range from $32 \%$ to 90\% (Ilhan et al., 2008; Veli et al., 2008).

In a parallel procedure water is electrolyzed and small oxygen bubbles are formed on the anode, while hydrogen is released in the cathode (Mollah et al., 2004) in a process called electroflotation. This process also aids in the removal of flocculated contaminants. Figure 2 presents a schematic diagram of a lab-scale two-electrode electrocoagulation cell. 


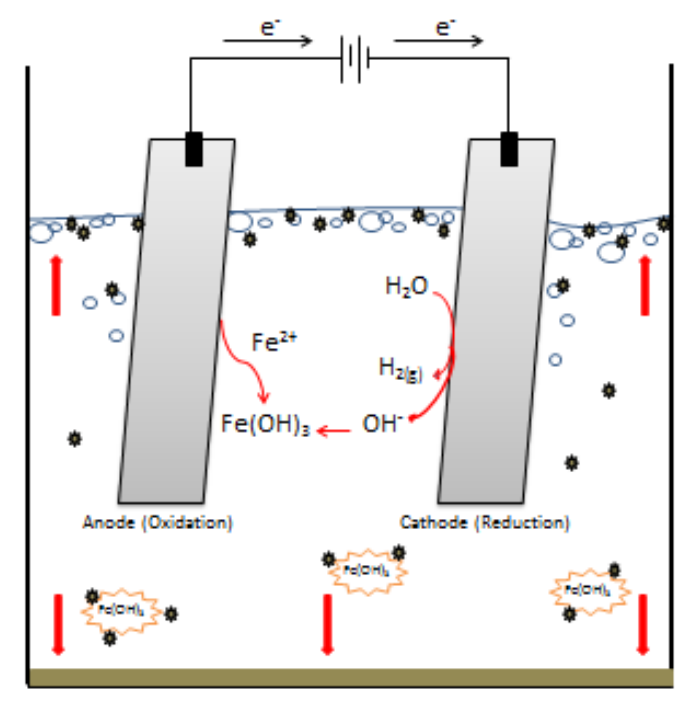

Figure 1. Diagram for an electro-coagulation cell. Modified from Mollah et al. (2004).

Two mechanisms have been proposed for the theoretical metal hydroxide production in the electrodes. When iron is used the following reactions are given (Ilhan et al., 2008):

\section{Mechanism 1}

Half reaction on the anode:

$$
4 \mathrm{Fe}_{(s)} \rightarrow 4 F e_{(a q)}^{2+}+8 e^{-}
$$

Overall chemical reaction:

$$
4 \mathrm{Fe}_{(a q)}^{2+}+10 \mathrm{H}_{2} \mathrm{O}_{(l)}+\mathrm{O}_{2} \rightarrow 4 \mathrm{Fe}(\mathrm{OH})_{3}+8 \mathrm{H}_{(a q)}^{+}
$$

Half reaction on the cathode:

$$
8 H_{(a q)}^{+}+8 e^{-} \rightarrow 4 H_{2}
$$

Overall chemical reaction:

$$
4 \mathrm{Fe}_{(s)}+10 \mathrm{H}_{2} \mathrm{O}_{(\mathrm{l})}+\mathrm{O}_{2(g)} \rightarrow 4 \mathrm{~F}(\mathrm{OH})_{3(s)}+4 \mathrm{H}_{2(g)}
$$




\section{Mechanism 2}

Half reaction on the anode:

$$
F e_{(s)} \rightarrow F e_{(a q)}^{2+}+e^{-}
$$

Overall chemical reaction:

$$
\mathrm{Fe}_{(a q)}^{2+}+2 \mathrm{OH}_{(a q)}^{-} \rightarrow \mathrm{Fe}(\mathrm{OH})_{2(s)}
$$

Half reaction on the cathode:

$$
2 \mathrm{H}_{2} \mathrm{O}_{(l)}+2 e^{-} \rightarrow \mathrm{H}_{2(g)}+2 \mathrm{OH}_{(a q)}^{-}
$$

Overall chemical reaction:

$$
\mathrm{Fe}_{(s)}+2 \mathrm{H}_{2} \mathrm{O}_{(l)}+\mathrm{O}_{2(g)} \rightarrow \mathrm{Fe}(\mathrm{OH})_{2(s)}+\mathrm{H}_{2(g)}
$$

The metal hydroxides produced in real life conditions are very dependent on the chemical and physical characteristics of the medium, specially to the conductivity and $\mathrm{pH}$ (Ilhan et al., 2008; Mollah et al., 2001, 2004). The process may form monomeric ions like $\mathrm{Fe}(\mathrm{OH})_{3}$ or polymeric hydroxyl compounds: $\mathrm{Fe}\left(\mathrm{H}_{2} \mathrm{O}\right)_{6}{ }^{3+}, \mathrm{Fe}\left(\mathrm{H}_{2} \mathrm{O}\right)_{5}(\mathrm{OH})^{2+}, \mathrm{Fe}\left(\mathrm{H}_{2} \mathrm{O}\right)_{4}(\mathrm{OH})_{2}{ }^{+}$, to name some.

\section{Advanced oxidation with Sodium Ferrate}

The previous two pre-treatment options focused on the physical removal of contaminants as a mean to reduce $\mathrm{COD}$ and/or $\mathrm{BOD}_{5}$ concentrations. The use of ferrate $\left(\mathrm{Fe}^{\mathrm{VI}} \mathrm{O}_{4}{ }^{2-}\right)$ focuses on the oxidation of non-biodegradable organic compounds to reach the same goal.

Iron is usually found in the +2 (ferrous) and +3 (ferric) oxidation states. Under strong oxidizing conditions, iron can reach a higher oxidation state as +6 (ferrate) (Batarseh et al., 2007). A ferrate salt is a very strong chemical oxidant $(\mathrm{EOP}=2.20 \mathrm{~V}$ under acidic conditions $)$ that has the additional advantage of producing ferric as it is being reduced, which serve as a coagulant agent 
either as ferric oxide or ferric hydroxide (Batarseh et al., 2007; Jiang et al., 2006; Tiwari et al., 2005). Equation 9 shows the decomposition of ferrate under acidic conditions:

$$
\mathrm{FeO}_{4}^{2-}+8 \mathrm{H}^{+}+3 \mathrm{e}^{-} \rightarrow \mathrm{Fe}^{3+}+4 \mathrm{H}_{2} \mathrm{O}
$$

It is not a common procedure for the treatment of leachate but has recently been studied for disinfection purposes in wastewater and water treatment (Jiang, 2007; Lee et al., 2009), where two main compounds are usually used: Sodium ferrate $\left(\mathrm{Na}_{2} \mathrm{FeO}_{4}\right)$ and potassium ferrate $\left(\mathrm{K}_{2} \mathrm{FeO}_{4}\right)$. For disinfection purposes, the use of ferrate avoids the harmful by-products (DBP's) associated with chlorine or other disinfectants such as bromine, iodine and ozone (Jiang and Lloyd, 2002).

\section{Additional Measurements for Efficiency Comparison}

\section{Odour Strength Measurements}

Odors remain one of the top complaints to air quality regulators and government bodies around The United States and internationally (McGinley et al., 2000; Nicell, 2009). Even though it is such a common problem, odour quantification and evaluation has been considered inconsistent and highly subjective. In recent years, the publication of standard practices by the American Society of Testing and Materials (ASTM E544-10, 2010; ASTM E679-04, 2011), as well as European versions (CEN EN 13725), have helped in formalizing these procedures.

Odour testing is normally done in a laboratory environment under controlled conditions. The sample is tested in terms of human perception, either by comparing the perceived odor intensity to a reference scale or by determining the detection and recognition thresholds of a specific 
odour. An odor panel is employed as a representative sample of the population, as the olfactory response to odors is normally distributed (McGinley et al., 2000). This allows for a statistical analysis to determine the perceived odor strength of the sample.

On-site measurements are also becoming more common with the use of portable olfactometry equipment or scentometer. These units, similarly to the bigger laboratory sampling tables, rely on clean air or oxygen to purge the assessor's nose prior to testing. The sample is introduced at a particular dilution ratio and the person tries to determine if the odor is detected and/or recognized. If not, the dilution ratio is gradually decreased until the odour is detected. At this point, the odour threshold is determined (St. Croix Sensory Inc., 2008).

\section{Biodegradability Observations}

The relationship of BOD to COD can be used to estimate the biodegradable fraction or "biodegradability" of a specific sample. A ratio greater or equal to 0.5 is considered to be easily treated by biological means, while a ratio of 0.3 or lower is considered not biodegradable and/or to possess toxic components, and a period of acclimation may be required for biodegradability (Tchobanoglous et al., 2004). 


\section{OBJECTIVES}

- The main goal of the research was to assess the use of physical-chemical methods for the pre-treatment of landfill leachate from BRRMF (Winnipeg) that would be effective and complies with regulatory limits for discharge to the sewer system.

- Determine the best individual treatments in terms of COD and ammonia removal, and evaluate the effectiveness of combining these treatments to optimize the characteristics of the treated leachate.

- Evaluate the effect of the pre-treated leachate on the short term and long term performance of a lab-scale BNR system modeled after the local wastewater treatment plant process. 


\section{CHAPTER 2. MATERIALS AND METHODS}

\section{Landfill Information}

Brady Road Resource Management Facility (BRRMF) in Winnipeg, Manitoba, Canada opened in 1973 and is currently the only active landfill for the city. It has a working area of 112 ha in a total available land for landfilling of 790 ha collecting more than 400000 tons of waste per year. An approximate volume of $60,000 \mathrm{~m}^{3}$ of leachate is collected annually at this site. The current leachate management consists of an average of 8 trucks $\left(30 \mathrm{~m}^{3}\right.$ each) that come into the landfill daily and pump out the leachate from collection wells. The trucks then need to go across the city and discharge in the North End Water Pollution Control Centre (NEWPCC), where it is mixed with the incoming municipal wastewater.

\section{Sampling Procedure}

Leachate chemistry and composition vary within any landfill, so in order to get a representative sample, 20 L High Density Polyethylene (HDPE) carboys were filled 50/50 from two specific leachate collection wells. The samples were taken after the scheduled time for extraction by the trucks. This allowed "fresh" leachate to enter the well from the cells and be pumped for the sample.

From the operation controls of the landfill it is known that the first well has the highest reported BOD values, while the second well has the highest COD and heavy metals concentrations. The carboys were filled to the top in order to reduce headspace in the containers and maintain anaerobic conditions. Once in the lab, the containers were stored at $4{ }^{\circ} \mathrm{C}$ to limit biological degradation of the sample. Table 1 presents the average parameters measured for the leachate 
from BRRMF. The two main samples were taken on August 2013 (300 L) and February 2014 $(100 \mathrm{~L})$, to further evaluate the variation in leachate composition between summer and winter.

\section{Leachate Characterization}

Table 2 presents a summary of leachate parameters measured for the present research as well as data from previous laboratory controls for BRRMF's leachate. The last column shows the limits for discharging into the sewer system, according to the current city By-laws (No. 92/2010). All data in $\mathrm{mg} / \mathrm{L}$, except $\mathrm{pH}$.

Table 2. Characteristics of tested leachate

\begin{tabular}{c|ccc}
\hline Parameter & $\begin{array}{c}\text { Current Study } \\
(\text { Jul. 2013-Sep.2014) }\end{array}$ & $\begin{array}{c}\text { * Landfill } \\
\text { laboratory } \\
\text { control } \\
(\mathbf{2 0 1 2 - 2 0 1 3 )}\end{array}$ & $\begin{array}{c}* * \text { Discharge limits } \\
\text { for sewer system } \\
(\boldsymbol{m g} / \mathbf{L})\end{array}$ \\
\hline pH & $7.2 \pm 0.1$ & $7.5 \pm 0.2$ & $5.5-11.0$ \\
COD & $2,366 \pm 1,260$ & - & Not Available \\
SCOD & $2,133 \pm 1,230$ & - & Not Available \\
TSS & $280 \pm 207$ & $319 \pm 334$ & 350 \\
BOD5 & $248 \pm 20$ & $245 \pm 307$ & 300 \\
TN & $772 \pm 65$ & $647 \pm 184$ & 60 \\
NH3-N & $699 \pm 112$ & $561 \pm 146$ & Not Available \\
TP & $5.9 \pm 1.7$ & $3.4 \pm 1.2$ & 10 \\
\hline
\end{tabular}

* Brady Road Resources Management Facility laboratory controls, January 2012 to March 2013

**City of Winnipeg, MB. By-Law No.92/2010

The leachate parameters determined in this research are consistent with the ones of an "intermediate" leachate (around 5 to 10 years of age), according to the literature (Kjeldsen et al., 2002; Kurniawan et al., 2006; Renou et al., 2008). Even though the landfill is over 40 years old, the leachate used for this research was taken from cells currently in operation, which would correspond to this age range. Changes in ammonia and phosphorus levels are suspected to be 
related to the disposal of biosolids in recent years from the West End Water Pollution Control Center. Variability is also an effect of seasonal changes. The values may change as well due to the specific well where the samples are taken from, as different types of waste are placed in different cells. Additionally, as was mentioned before the quantity and the characteristics of the leachate are also directly related to the MSW and the conditions of the site. No heavy metal characterization was determined, as the heavy metals are considered outside the boundaries of this study.

The BOD/COD ratio is estimated at 0.1 which indicated that a high percentage of the organic matter present is not easily biodegradable. This is the reason why a physical and/or chemical pretreatment is necessary.

\section{Individual Pre-treatment Methods}

\section{Analytical methods}

All chemicals used were of analytical grade. Total COD, soluble COD, Total Nitrogen (TN) and Total Phosphorus (TP) were measured using $\mathrm{HACH}{ }^{\circledR}$ digestion vials. $\mathrm{BOD}_{5}$ and $\mathrm{TSS}$ measurements were carried out following laboratory procedures according to the Standard Methods (Eaton et al., 2012). Dissolved organic carbon (DOC) analyses were performed using the Fusion Total Organic Carbon Analyzer (TELEDYNE TEKMAR). Ammonnia (NH3 -N), was

measured using an automatic flow injection analyser (Quick Chem 8500, LACHAT Instruments). 


\section{Air Stripping}

Clear polyvinyl chloride (PVC) reactors $(20 \mathrm{~cm}$ diameter, $40 \mathrm{~cm}$ height, $4.0 \mathrm{~L}$ working volume) were built for evaluating this treatment option - Figure 2 . The reactors were filled to the $4 \mathrm{~L}$ mark with leachate and the air bubbled through the liquid by two small spherical diffusers near the bottom of the reactors, connected to a small air pump - See Figure 4. Mixing speed was set at $125 \mathrm{rpm}$.

Four conditions were tested: (1) no mixing, no air flow; (2) mixing, no air flow; (3) mixing, 0.25 $\mathrm{L}$ air/L/min and (4) mixing, $1 \mathrm{~L}$ air $/ \mathrm{L} / \mathrm{min}$. Four $\mathrm{pH}$ conditions were evaluated as well: original $\mathrm{pH}$ of the sample (7.0), 10.0, 11.0 and 12.0. The tests were conducted for 48 hours, with samples taken at two hour intervals to determine the best treatment duration. For $\mathrm{pH}$ adjustment, a $25 \%$ w/w solution of sodium hydroxide $(\mathrm{NaOH})$ was used. The reactors were maintained at $21 \pm 2{ }^{\circ} \mathrm{C}$.

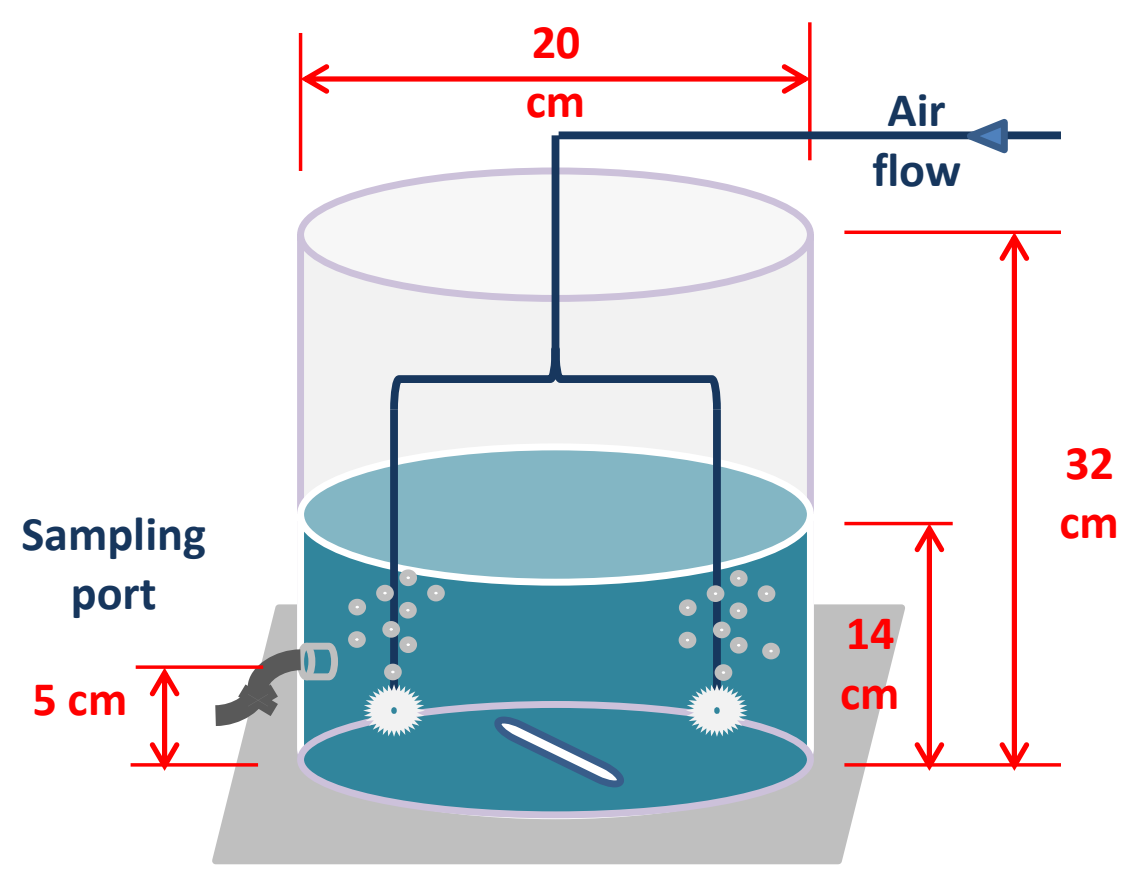

Figure 2. Air Stripping set up. 


\section{Chemical Coagulation}

Chemical coagulation was carried out using Ferric Chloride solution $\left(\mathrm{FeCl}_{3}\right)$. A set of preliminary tests were conducted without $\mathrm{pH}$ adjustment of the sample (approximate $\mathrm{pH}=7.2$ ) with different coagulant dosages to determine the optimal range. Based on the results, a range from 34 to $172 \mathrm{mg}$ as $\mathrm{Fe} / \mathrm{L}$ (corresponding to a range from 100 to $500 \mathrm{mg} \mathrm{FeCl}_{3} / \mathrm{L}$ ) was determined. Additionally, based on the assumption that colloidal particles are negatively charged, the chemical coagulation tests were carried out under acidic conditions, at an expected optimal value of 5.0. Following the standard procedure on ASTM D2035-13, a typical Jar test apparatus was then employed to evaluate the coagulant doses at different $\mathrm{pH}$ values: 7.0 (original $\mathrm{pH}$ of the sample ), 6.0, 5.0 and 4.0. For $\mathrm{pH}$ reduction an $18 \% \mathrm{w} / \mathrm{w}$ hydrochloric acid $(\mathrm{HCl})$ solution was used. See Figure 3 for typical set up.

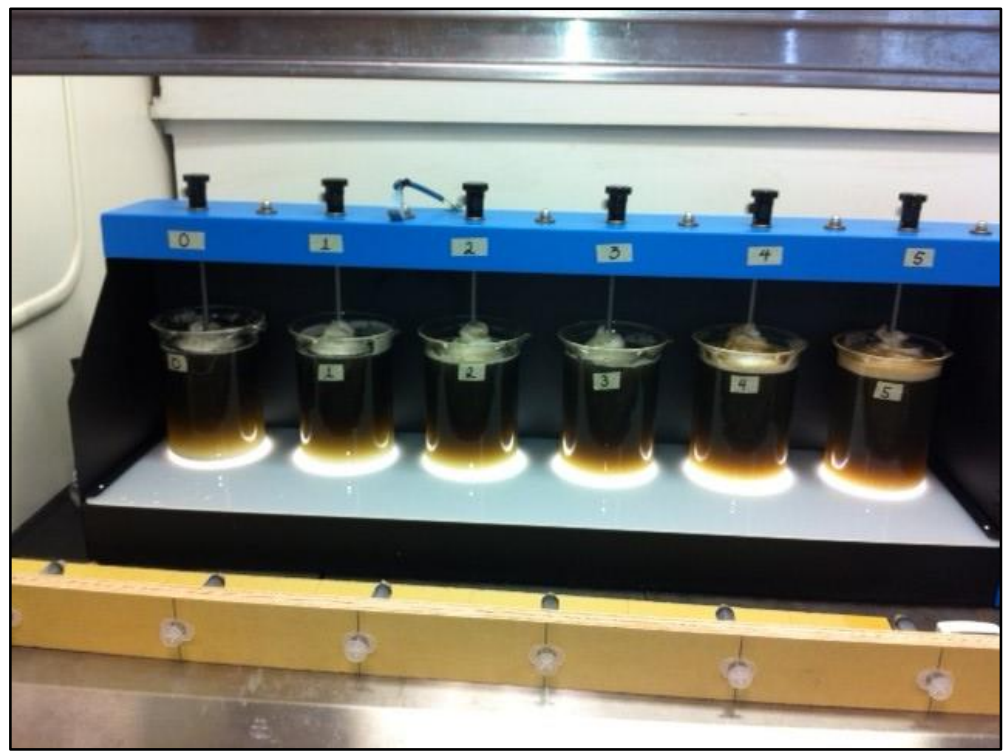

Figure 3. Set up for chemical coagulation. 


\section{Electro-coagulation}

The electro-coagulation tests were conducted using 2 high purity Iron electrodes with an effective surface area of $45 \mathrm{~cm}^{2}$ and a $2.0 \mathrm{~cm}$ gap between them in a $1 \mathrm{~L}$ glass beaker - See Figure 4. The following parameters were evaluated: (1) contact time of 5, 15 and 30 minutes, (2) $\mathrm{pH}$ values: original of the sample (7.0), 8.0 and 6.0 and (3) current density: 50, 100, 200 and 300 $\mathrm{A} / \mathrm{m}^{2}$. Current was supplied by a KEPCO DC power source (Model BOP 100-2D, 0 to $\pm 100 \mathrm{~V}, 0$ to $\pm 2 \mathrm{~A})$.

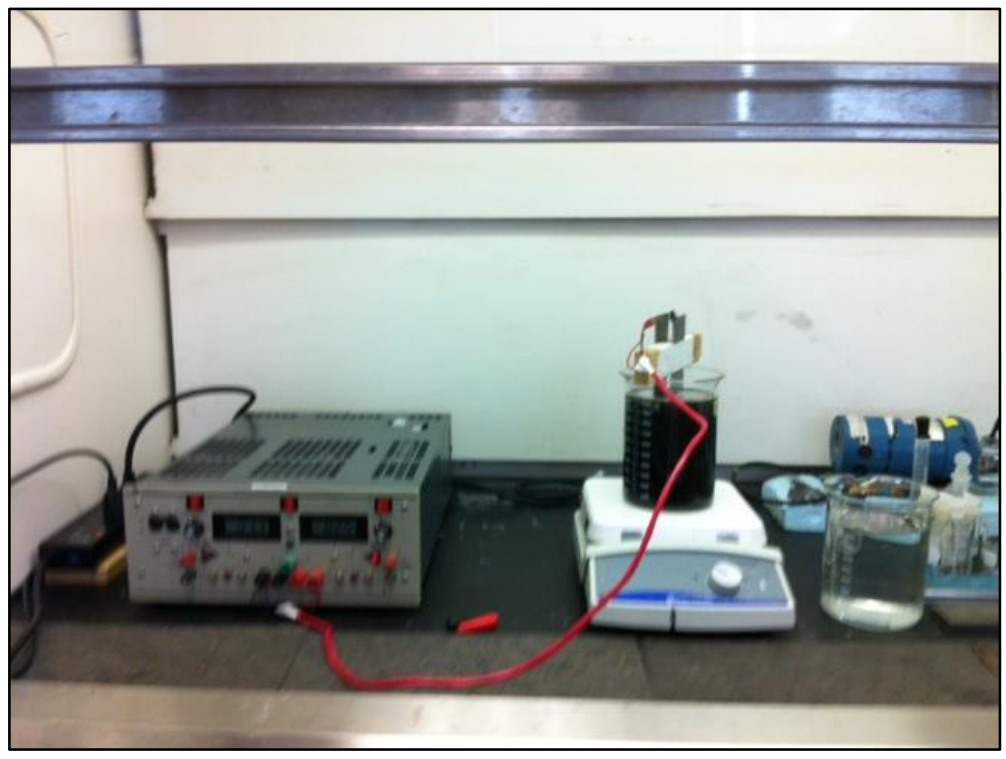

Figure 4. Electro-coagulation set-up. 


\section{Advanced oxidation with sodium ferrate}

Sodium ferrate $\left(\mathrm{Na}_{2} \mathrm{FeO}_{4}\right)$ was produced in the laboratory by following a wet oxidation procedure where hypochlorite was used to oxidize an iron salt under a strong alkaline environment (Jiang and Lloyd, 2002). Due to the rapid degradation of this compound, the solution had to be prepared and used on the same day. Ferrate concentration was measured after each batch with the use of a UV-Visible Spectrophotometer (Ultrospec 2100 pro, Biochrom Ltd.), at a wavelength of $510 \mathrm{~nm}$, molar absorption coefficient: $1150 \mathrm{M}^{-1} \mathrm{~cm}^{-1}$, cell path length: $10 \mathrm{~cm}$. The dose range tested in the jar test system was from 50 to $200 \mathrm{mg} \mathrm{Fe} / \mathrm{L}$ in $50 \mathrm{mg}$ increments, and the $\mathrm{pH}$ conditions were the original $\mathrm{pH}$ of the sample (7.4), 6.0, 5.0 and 4.0 (Figure 5). For $\mathrm{pH}$ reduction, an $18 \%$ w/w solution of $\mathrm{HCl}$ was used. For this test, the additional measurement of dissolved organic carbon (DOC) was introduced to better evaluate the effect on the organic fraction of the leachate.

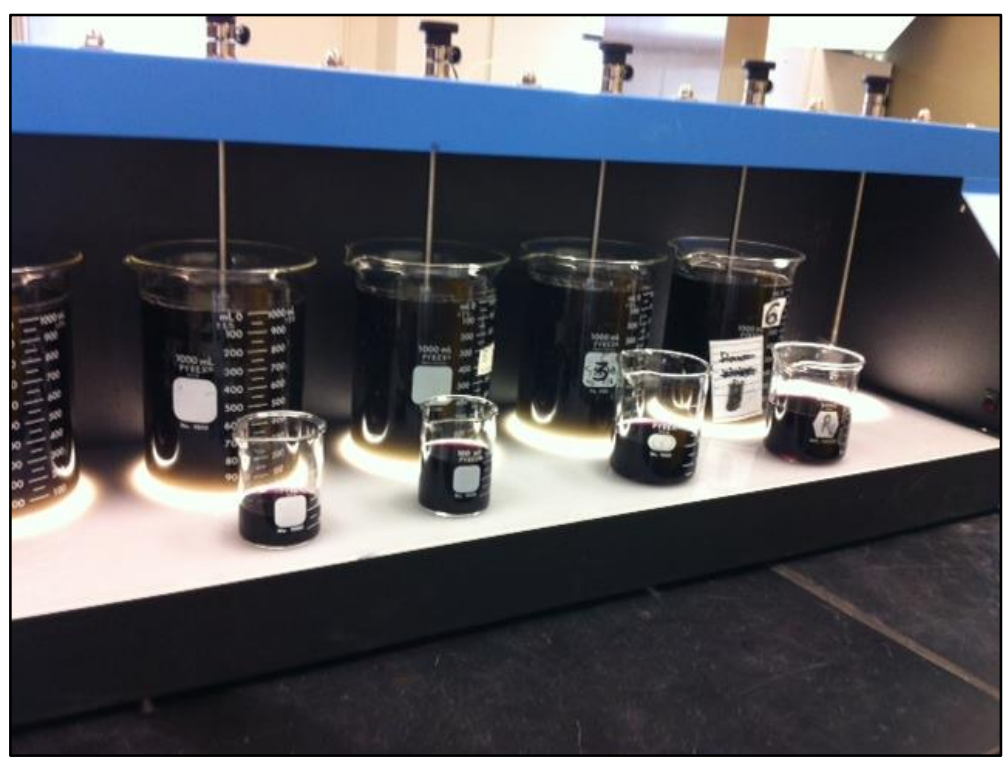

Figure 5. Set up for sodium ferrate solution. 


\section{Additional Measurements for Efficiency Comparison}

\section{Odour Strength assessment}

For the evaluation of odour strength, the Nasal Ranger ${ }^{\circledR}$ Field Olfactometer from St. Croix Sensory was used, shown in Figure 6. The unit creates a calibrated series of discrete dilutions by mixing the odorous ambient air with odor-free (carbon) filtered air. Each discrete dilution level is described as a "Dilution-to-Threshold," D/T, ratio. The "Dilution-to-Threshold" ratio is a measure of the number of dilutions needed to make the odorous ambient air "non-detectable".

\section{Volume of Carbon-Filtered Air \\ D/T = - Volume of Odorous Air}

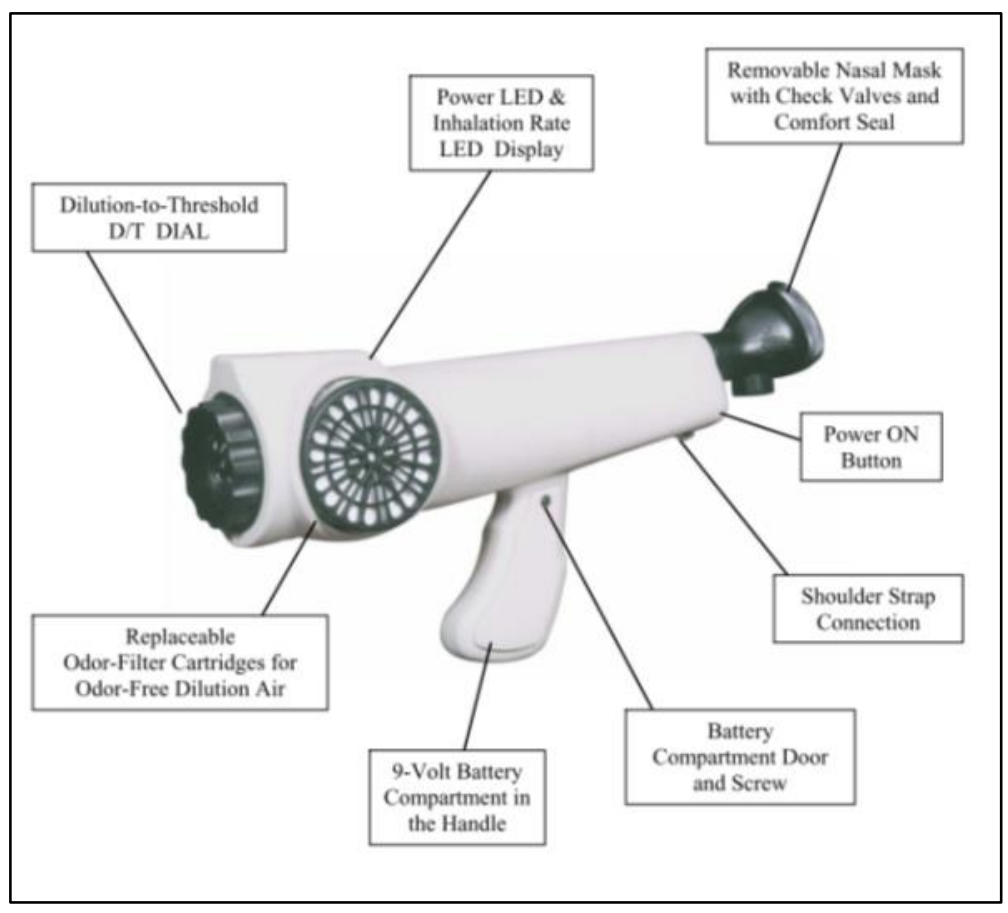

Figure 6. Nasal Ranger ${ }^{\circledR}$ Field Olfactometer component diagram

The measurement procedure is explained in Apendix B. 


\section{Evaluation of Pre-treatment Combination Efficiency}

Based on the removal percentages of the two parameters considered to be most representative, COD and ammonia, chemical coagulation and air stripping were selected as the best treatment options. These two options were repeated under the optimal conditions and combined to evaluate for any increase or decrease in removal efficiency:

\section{Combination 1}

1. Air stripping for 48 hours, air flow of $1 \mathrm{~L} / \mathrm{L} * \mathrm{~min}, \mathrm{pH}$ adjusted to 11.0 with $\mathrm{NaOH}$

2. Chemical coagulation under 3 different options:

Option A: $\mathrm{pH}$ adjusted down to 5.0 with $\mathrm{HCl}$ solution to use $\mathrm{FeCl}_{3}$

- Option B: pH not adjusted but still using $\mathrm{FeCl}_{3}$

○ Option C: $\mathrm{pH}$ not adjusted, using $7 \mathrm{~g} / \mathrm{L}$ of $\mathrm{CaCO}_{3}$ as a coagulant

\section{Combination 2}

1. Chemical coagulation under 2 options:

○ Option D: $\mathrm{pH}$ adjusted down to 5.0 to use $\mathrm{FeCl}_{3}$, then up to $\mathrm{pH} 11.0$ with $\mathrm{NaOH}$

O Option E: $\mathrm{pH}$ adjusted using $7 \mathrm{~g} / \mathrm{L}$ of $\mathrm{CaCO}_{3}$

2. Air stripping for 48 hours, at an air flow of $1 \mathrm{~L} / \mathrm{L} * \min$ 


\section{Pre-Treatment Effect on Nitrification Kinetics}

Phase II was divided into Stage 1: effect of one time shock load of leachate on nitrification kinetics and Stage 2: effect of continuous addition of leachate on nitrification kinetics.

For Stage 1, one sequencing batch reactor was used to simulate the conditions of a Biological Nutrient Removal (BNR) system. Waste Activated Sludge (WAS) was taken from the West End Water Pollution Control Centre (WEWPCC) in Winnipeg to seed the reactors, as this is the only plant in the city to use a BNR system. The wastewater treated in the SEWPCC was used as feed. The bench scale system was set up using a $4 \mathrm{~L}$ working volume reactor with an HRT of 12 hours, SRT of 10 days, an anaerobic phase of $1.5 \mathrm{~h}$ and an aerobic phase of $4 \mathrm{~h}$. The temperature was maintained at room temperature $\left(20 \pm 1^{\circ} \mathrm{C}\right)$, and the Dissolved Oxygen (DO) concentration over $4 \mathrm{mg} \mathrm{O}_{2} / \mathrm{L}$ during aerobic phase. This reactor was operated and monitored for over 30 days (3 times the SRT) before starting the kinetic testing to ensure stable conditions.

For the kinetic test, the biomass from the main reactor was divided into three $1 \mathrm{~L}$ beakers, one served as control while the other two served as testing reactors. The Control reactor was fed only wastewater from the SEWPCC, while each one of the two testing reactors was fed with a specific mixture percentage of wastewater and leachate (either untreated o pre-treated with the combination of air stripping and chemical coagulation). Pre-treated leachate was stored in a plastic carboy until the time it was needed for the test. Storage time was approximately 2 weeks. The leachate to wastewater mixing ratios (by volume) were: $0.5 \%, 1.0 \%, 5.0 \%$ and $10.0 \%$. Two sets of Controls are reported in the discussion for untreated and for pre-treated tests. There being four mixing ratios to evaluate, one day the tests were done for $0.5 \%, 1 \%$ and a control. On a different day, the tests were carried out for $5.0 \%, 10.0 \%$ and a second control. 
There were at least 7 days between each test to allow the recovery of the biomass. During the testing period, samples were taken from each of the reactors at $15 \mathrm{~min}$ intervals. The parameters measured included soluble COD, ammonia nitrogen, nitrate, nitrite and Total Phosphorus.

It is important to explain the reasoning behind the mixing percentage rates used for this experiment. To determine these values the current and future condition of the leachate treatment methods employed by the city were considered. The current Dry Weather Flow (DWF) of sewage to the South End Water Pollution Control Center (SEWPCC) is estimated at $60000 \mathrm{~m}^{3} / \mathrm{d}$, while the leachate collected from BRRMF is for the moment around $164 \mathrm{~m}^{3} / \mathrm{d}\left(60000 \mathrm{~m}^{3} / \mathrm{year}\right)$. According to these values, if the leachate produced at the landfill was to be mixed with the sewage under current conditions it would only represent around $0.30 \%$ by volume of the flow going into the treatment plant. Future leachate flows projections were provided by KGS Group Consulting Engineers based on their available information. The volume of leachate to be collected at the landfill is expected to be between 275 and $550 \mathrm{~m}^{3} / \mathrm{d}$ (100 000 to $20000 \mathrm{~m}^{3} /$ year) as the collection and treatment methods improve. At these higher values, the volume of leachate compared to sewage is still very small, between $0.45 \%$ and $0.90 \%$. These findings provided the lower end of the selected mixing percentages. For research purposes, higher mixing rates ( 5 and $10 \%$ ) were also evaluated in this investigation.

For Stage 2 a total of three bench-scale SBR systems were utilized: a control reactor fed only wastewater, one fed wastewater blended with untreated leachate (reactor named Untreated) and the other one fed wastewater blended with pretreated leachate (reactor named Treated). The mixing percentages of leachate used in the Untreated and Treated reactors were $2.5 \%$ and $5.0 \%$ by volume. Both forms of leachate (untreated and pretreated) were mixed with the wastewater in the respective feeding tanks twice a week. 
At the preparation stage, the three reactors were fed only wastewater to stabilize the biomass and determine a baseline during a 20 day period ( 2 times SRT). Then during the kinetic test each one of the mixing conditions described before were maintained for at least 20 days (2 SRT) while closely monitoring total and soluble COD, ammonia, phosphorus, TSS and VSS.

The test of mixing the leachate at $2.5 \%$ was carried out from day 20 to day 42 . Due to problems in the operation (failure of the refrigerator that kept the feed at a constant temperature and a problem with the feeding pumps) as well as seasonal variations in the wastewater parameters, the reactors had to be re-seeded to continue the experiments. A new acclimation period of the biomass occurred from day 60 to day 75. Finally, the second test mixing leachate at a rate of 5.0 $\%$ was initiated at day 77 and was completed on day 99, once the reactors were considered stable.

During the testing period, samples were taken from each of the reactors at $30 \mathrm{~min}$ intervals. The parameters measured included $\mathrm{pH}$, soluble COD, ammonia nitrogen, NOx (nitrite + nitrate) and Total Phosphorus. 


\section{CHAPTER 3. RESULTS AND DISCUSSION}

\section{Phase I: Leachate Pre-treatment}

\section{Air Stripping}

The overall ammonia removal rate was in the range of $65-86 \%$ after 48 hours, as shown in Figure 7. The highest ammonia removal rate was achieved under the condition of $\mathrm{pH}$ value of 11 and 12 with no significant difference $(2 \%)$. Considering the chemical cost associated with increasing $\mathrm{pH}, \mathrm{pH} 11$ was selected as the optimal $\mathrm{pH}$ condition for this treatment. One interesting observation was that for all the tests with $\mathrm{pH}$ adjustment, aeration did not improve the ammonia removal efficiency significantly as expected. On contrast, at $\mathrm{pH} 11$ and 12, reactors without aeration showed slightly better ammonia removal rate compared to the reactor with no aeration.

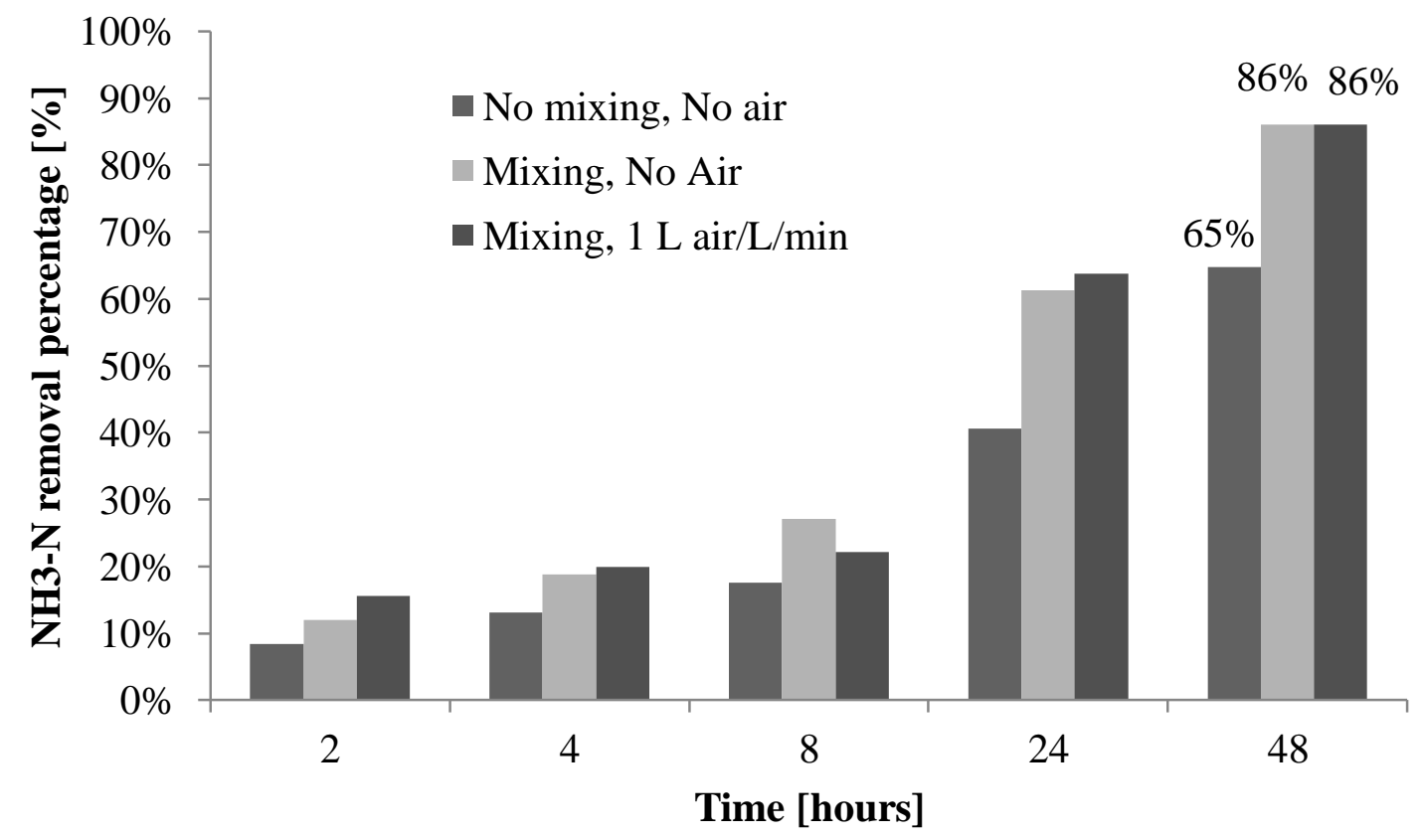

Figure 7. Ammonia removal under various conditions, pH: 11.0. 
Even more, just by increasing the $\mathrm{pH}$ to 11.0 but without any mixing or air flow, up to $65 \%$ ammonia removal was observed after 48 hours. This suggested that $\mathrm{pH}$ is the key factor controlling the efficiency of ammonia removal. Cheung et al. (1997) reached a similar conclusion indicating that the major area for desorption is the free liquid surface and not the additional surface area provided by the air bubbles. At high $\mathrm{pH}(>9.5)$ majority of ammonia is in the gas form and mechanical mixing is sufficient for assisting ammonia evaporate from leachate. This observation is important for the real practice as the cost associated with aeration can be expensive.

The overall COD removal rate was quite low in the range of 7-19\%-See Figure 8 . The results showed that at same $\mathrm{pH}$ condition, aeration resulted in slightly higher COD removal than the treatment without aeration. This can be explained by the concept that aeration facilities the removal of volatile of organic compound in the leachate.

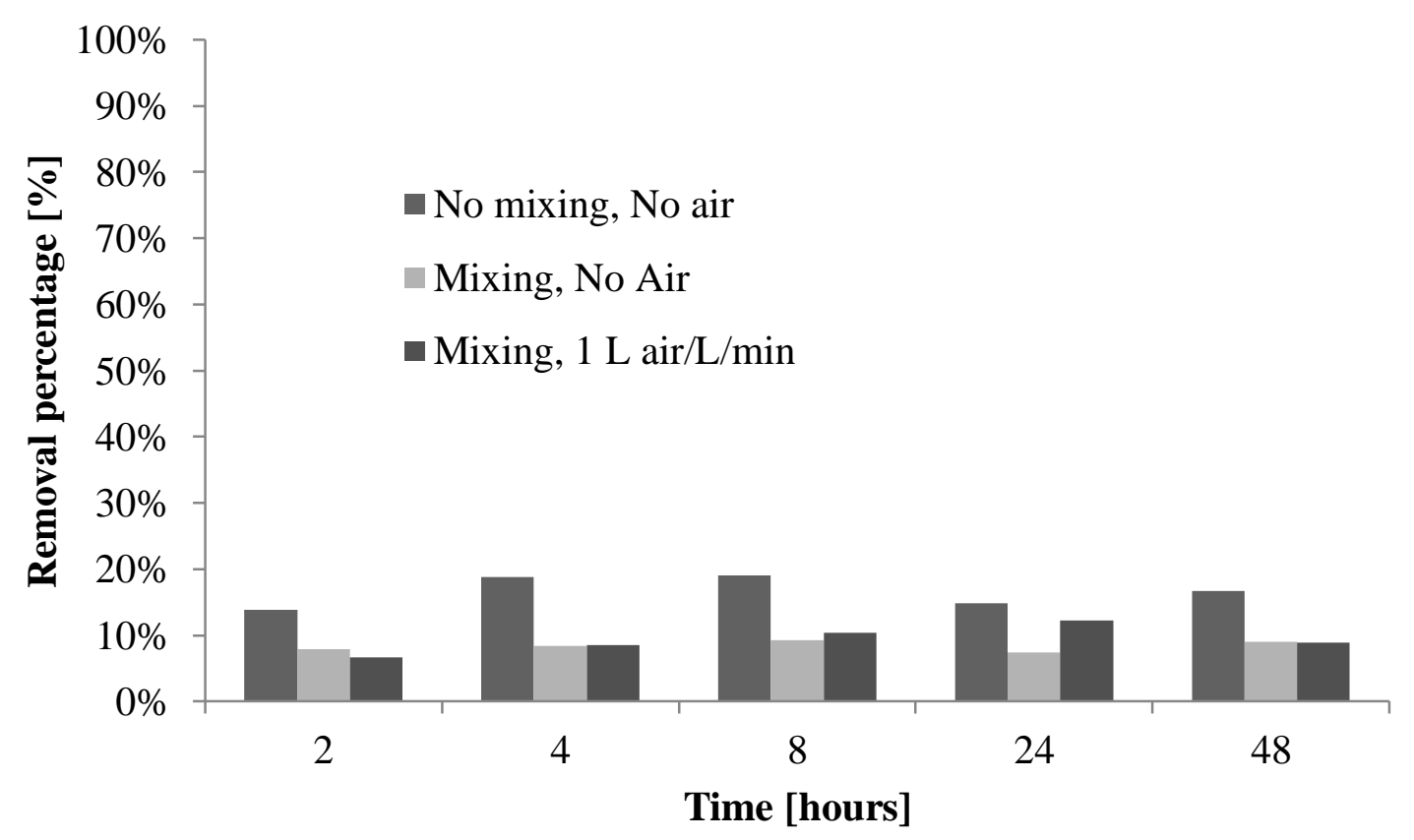

Figure 8. COD removal under various conditions, pH: 11.0. 
A thick foam layer was formed over the leachate surface while airflow was applied (Figure 9). The foam layer usually overflowed the reactors during the first 30 minutes of the aeration process, then settled and formed a constant layer $(5$ to $20 \mathrm{~cm})$ over the surface area. This foam layer dissipated after the air was turned off in less than one minute. Foaming could present serious operation and maintenance issues in a full size application. A solution could be utilizing anti-foaming agents, however for this research the use of additional chemicals was not preferred.

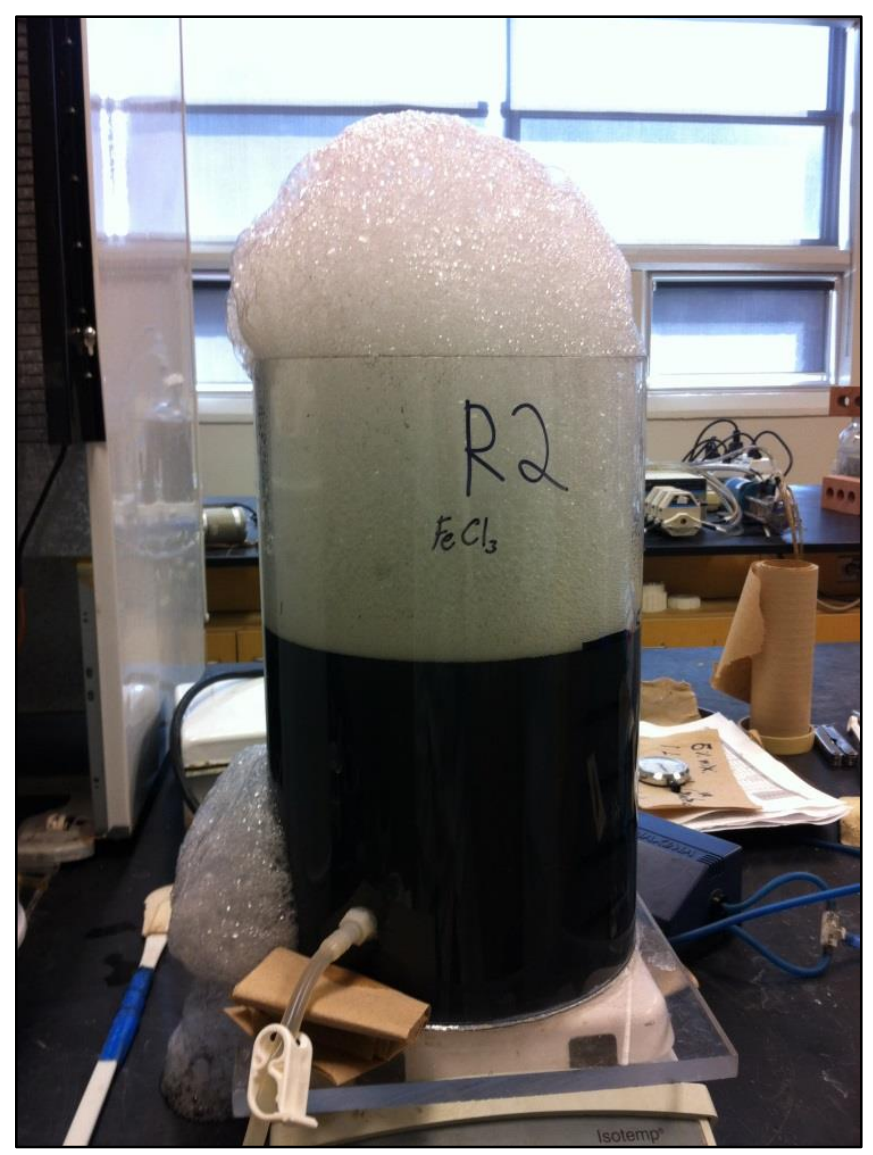

Figure 9. Excessive foaming during first minutes of air stripping. 


\section{Chemical coagulation}

A set of preliminary tests were conducted at the $\mathrm{pH}$ of the sample $(\approx 7.2)$ with different coagulant dosages to determine the optimal range. First the usual concentrations and dosages employed in wastewater treatment were tested, ranging from a concentration of 0 to $0.1 \mathrm{~g} \mathrm{FeCl}_{3}$ 0 (0 to $\left.0.03 \mathrm{~g} \mathrm{Fe}^{3+}\right)$ per liter of leachate. The results were satisfactory in terms of TSS removal percentages (most of the samples over 95\%), but some of the papers reviewed suggested that a much higher dosage provided better COD removal rates.

Amokrane et al. (1997), Tatsi et al. (2003) and Trebouet et al. (2001), indicated that the optimal coagulant dosage using $\mathrm{FeCl}_{3}$ was around 4 to $5 \mathrm{~g} \mathrm{FeCl}_{3}\left(1.5 \mathrm{~g} \mathrm{Fe}^{3+}\right)$ per liter of leachate. This dosage is around 100 times more than the usual concentrations tested in the first preliminary test. In order to test this new concentration, a second set of tests were conducted to study the effect of higher dosages of coagulant ranging from $0.1 \mathrm{~g}$ up to $6 \mathrm{~g}$ of $\mathrm{FeCl}_{3}\left(0.03\right.$ to $\left.2.01 \mathrm{~g} \mathrm{Fe}^{3+}\right)$.

In this research, COD removal percentages increased from $23 \%$ to $30 \%$ by increasing the dosage from $0.1 \mathrm{~g}$ to $3.0 \mathrm{~g}$ of $\mathrm{FeCl}_{3}$ per liter of leachate. Increasing the amount of coagulant 30 times just increased the removal percentage of $6 \%$, making this an inefficient step. Additionally, higher coagulant concentrations significantly increased the amount of foam produced. This problem was even worse at concentrations over $1.0 \mathrm{~g}$ of $\mathrm{FeCl}_{3}\left(0.34 \mathrm{~g} \mathrm{Fe}^{3+}\right)$, were the foaming problem was so extreme that sampling was ineffective (Figure 10). The practical implications of such a strong foaming problem are also important, as this would present a major concern not only in chemical costs but also in operation and maintenance of a constructed system. Anti-foaming agents could again provide a possible solution. 


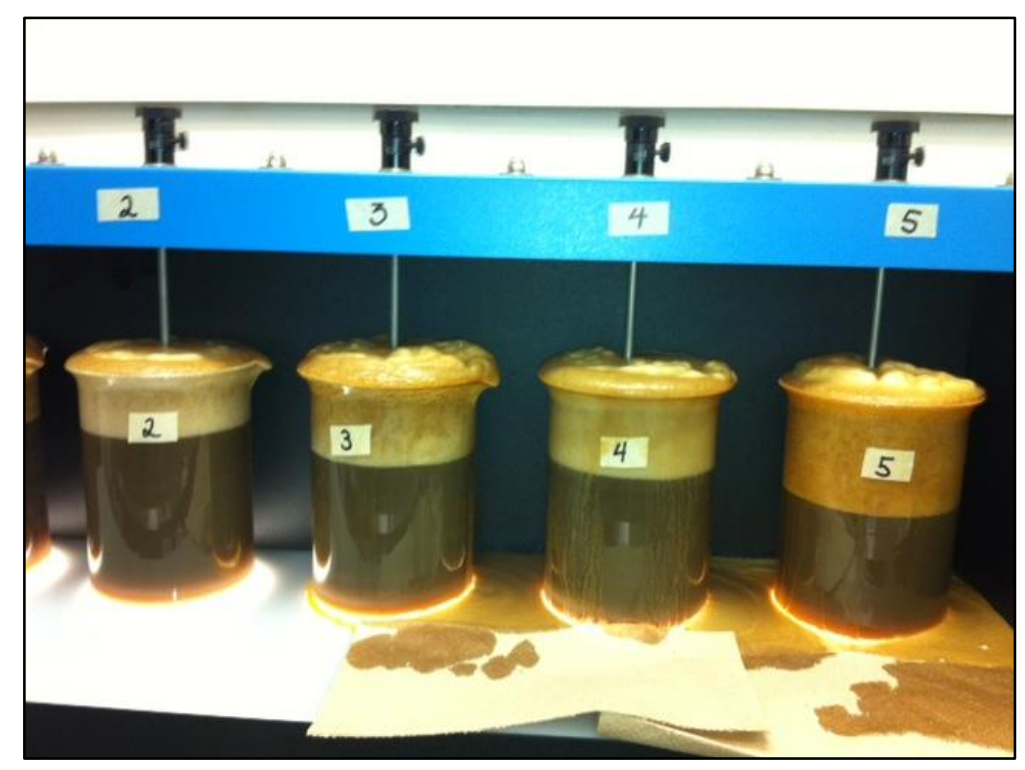

Figure 10. Excessive production of foam at doses over $1.0 \mathrm{~g} \mathrm{FeCl3.}$

To conclude the preliminary phase, tests were carried out at the expected optimal $\mathrm{pH}$ of 5.0, with doses of 0.05 and $0.25 \mathrm{~g} \mathrm{FeCl}_{3} / \mathrm{L}\left(0.02\right.$ and $0.09 \mathrm{~g} \mathrm{Fe}^{3+}$, respectively), to test the best range of coagulant dose at these conditions. In terms of COD removal, the dose of $0.05 \mathrm{~g}$ of coagulant improved only $2 \%$ when compared to the results at the $\mathrm{pH}$ of the sample (from $13 \%$ to $15 \%$ ). On the other hand, when $0.25 \mathrm{~g}$ of coagulant was used, the improvement was of around $10 \%$. Therefore, the final range of coagulant dose used in the tests was decided from 0 to $0.50 \mathrm{mg}$ $\mathrm{FeCl}_{3} / \mathrm{L}\left(0.17 \mathrm{~g} \mathrm{Fe}^{3+}\right)$, with $0.1 \mathrm{~g}$ increments.

The highest COD removal rate of $43 \%$ was obtained at $\mathrm{pH}$ of 5.0 with $\mathrm{FeCl}_{3}$ dosage of $500 \mathrm{mg} / \mathrm{L}$ (172 mg Fe/L) (See Figure 11). Tests carried out at the $\mathrm{pH}$ of 7.0 (leachate original $\mathrm{pH}$ ) and at 6.0 produced an average COD removal of only $10 \%$. When the $\mathrm{pH}$ is lowered from 5.0 to 4.0, COD removal also dropped from $43 \%$ down to $32 \%$. It was, therefore, concluded that $\mathrm{pH}$ of 5.0 with $500 \mathrm{mg} / \mathrm{L}$ of $\mathrm{FeCl}_{3}$ was the optimal condition for this pre-treatment option in terms of COD 
removal. These results are comparable to the ones reported by ( $\mathrm{Li}$ et al., 2010). Because coagulation targets particulate and ammonia in the leachate is in the dissolved form, therefore, ammonia removal rates from all the tests were insignificant (in the range from 1-4\%). It was noticed that dosing $\mathrm{FeCl}_{3}$ resulted in excellent TSS removal rate (76-99\%) in all the treatment condition. However, it also produced significant amount of sludge. This can be a drawback for the application of this technology.

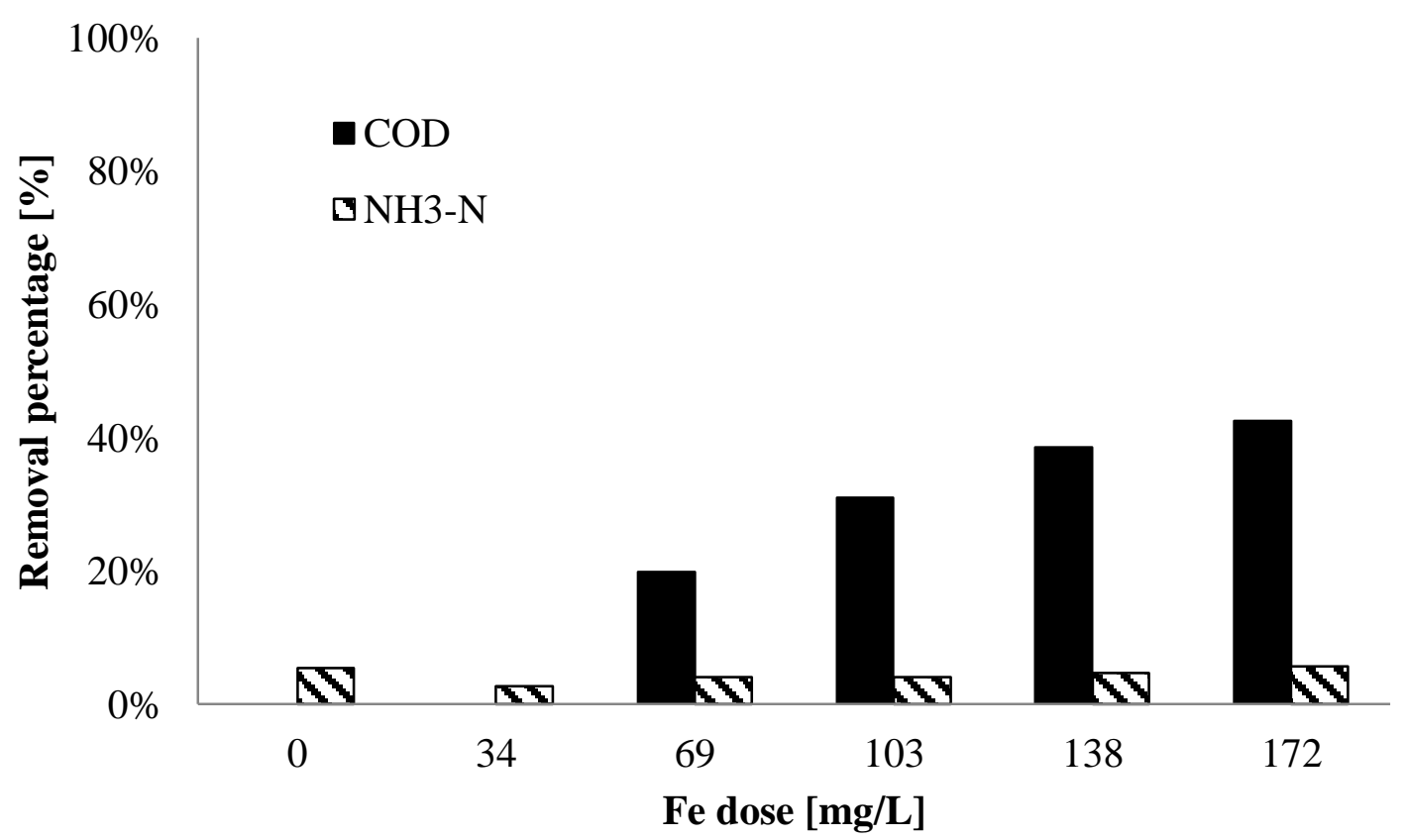

Figure 11. COD and ammonia removal results for chemical coagulation pre-treatment at pH 5.0.

The $\mathrm{pH}$ of each sample was measured after treatment, revealing that while the metal salt $\mathrm{FeCl}_{3}$ is hydrolyzed to produce insoluble Ferric Hydroxide $\left(\mathrm{Fe}(\mathrm{OH})_{3}\right)$, alkalinity is consumed in the form of Calcium Bicarbonate and mineral acidity is produced (Sawyer et al., 1994; Tchobanoglous et al., 2004). These reactions can be seen in Formulas 10 and 11. 
$2 \mathrm{FeCl}_{3}+2 \mathrm{Ca}\left(\mathrm{HCO}_{3}\right)_{2} \leftrightarrow 2 \mathrm{Fe}(\mathrm{OH})_{3}+3 \mathrm{CaCl}_{2}+6 \mathrm{CO}_{2}$

$\mathrm{FeCL}_{3}+3 \mathrm{H}_{2} \mathrm{O}=\mathrm{Fe}(\mathrm{OH})_{3}+3 \mathrm{H}^{+}+3 \mathrm{Cl}^{-}$

These two processes lower the $\mathrm{pH}$ of the sample, an effect that is more obvious in tests starting at 5.0 and 4.0. Previous tests still have sufficient alkalinity to buffer this process (Figure 12). This effect must also be considered when applying this technology if the $\mathrm{pH}$ must be restored to a neutral value after treatment, as the amount of chemical needed would increase.

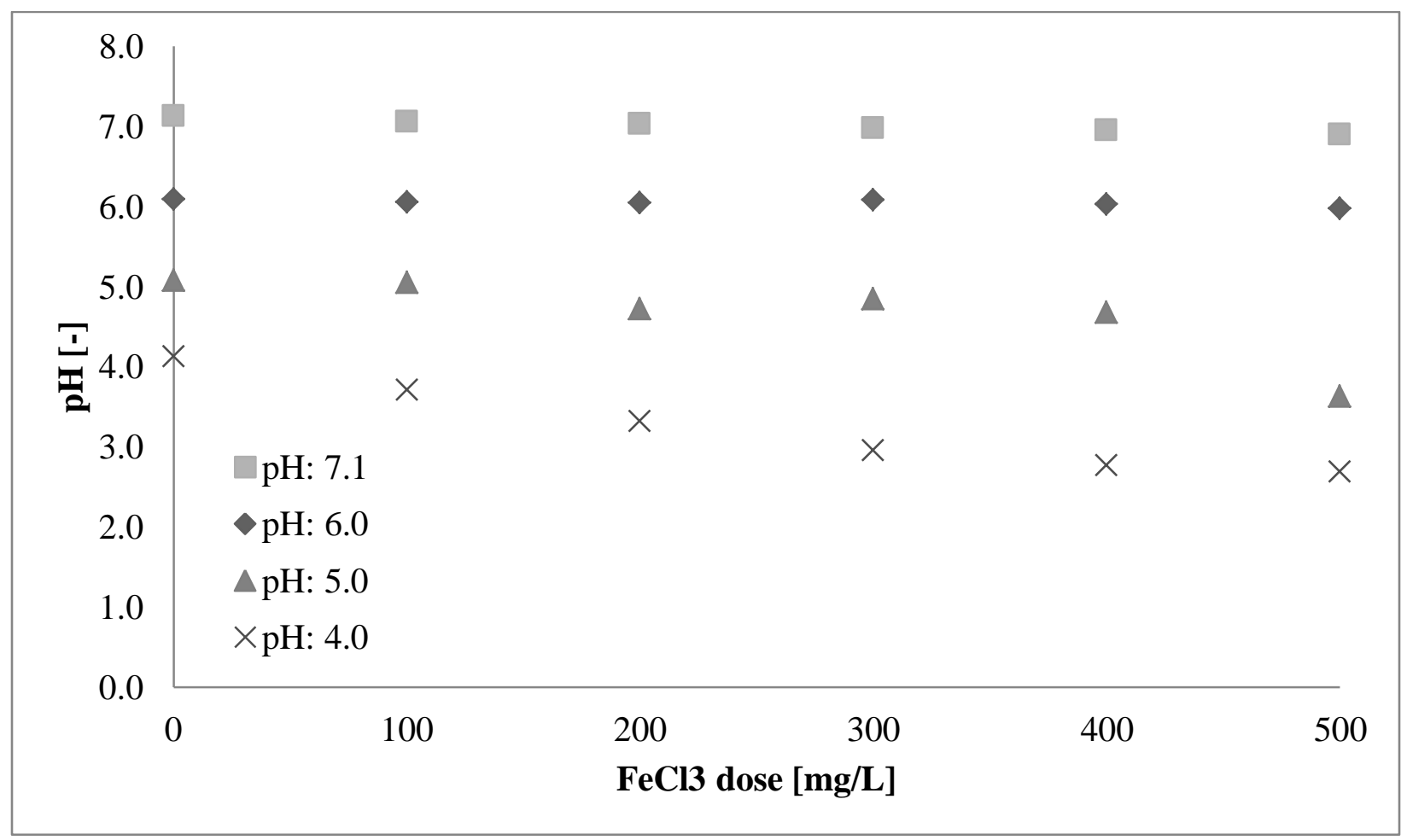

Figure 12. pH variation at different initial set points 


\section{Electro-coagulation}

An important parameter that affects the production of the metal hydroxides is the electrical conductivity of the sample, related to the ions concentration. For the leachate used in this experiment, the average was determined at $14.02 \mathrm{mS} / \mathrm{cm}$. This value is similar to the values reported by Veli et al. (2008): $25.11 \mathrm{mS} / \mathrm{cm}$, Ilhan et al. (2008): $19.62 \mathrm{mS} / \mathrm{cm}$ and Contreras et al. (2009): $6.19 \mathrm{mS} / \mathrm{cm}$.

The overall best results were achieved with the highest current density of $300 \mathrm{~A} / \mathrm{m}^{2}$ and the longest contact time of 30 min. without any $\mathrm{pH}$ modification. Under these conditions, COD removal reached $18 \%$. The results of ammonia removal were fair low (average of $2 \%$ ). Little improvement was obtained when the sample's $\mathrm{pH}$ was either increased or decreased. At a $\mathrm{pH}$ of 6.0, ammonia removal reached $12 \%$ but with a noticeable decrease in COD removal (Figure 13).

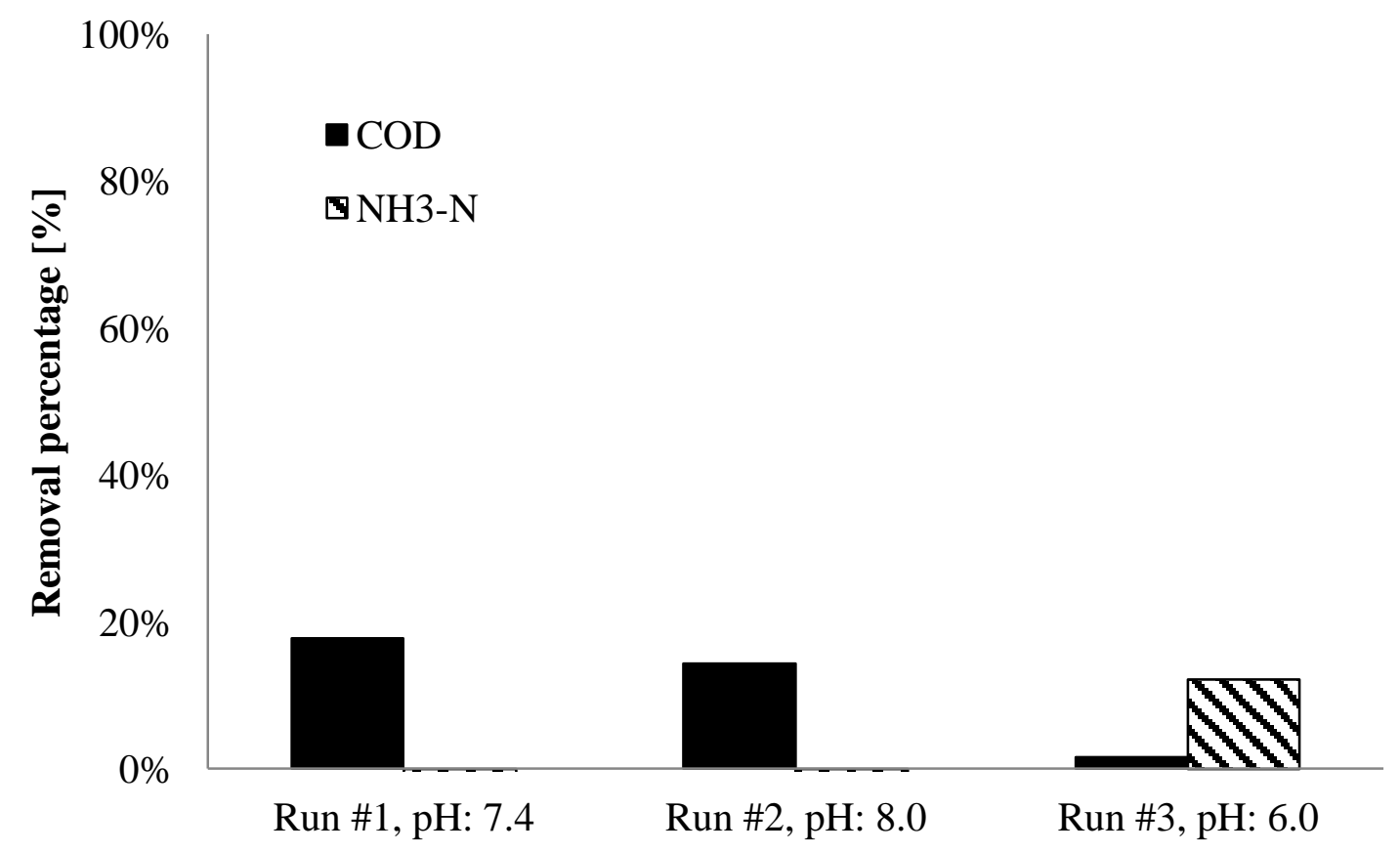

Figure 13. Results for electro-coagulation pre-treatment. Contact time: $30 \mathrm{~min}$, Current density: $300 \mathrm{~A} / \mathrm{m}^{2}$. 
Iron electrodes were used to produce the Ferric ions that acted as a coagulant. It was expected with the same amount of ferric ion produced under certain current density and time the COD removal rate should be similar to the chemical coagulation. However, the results obtained from electro-coagulation were much lower than those with chemical coagulation. At current density of $300 \mathrm{~A} / \mathrm{m}^{2}$ with 15 minutes, theoretically $261 \mathrm{mg} / \mathrm{L}$ of $\mathrm{Fe}^{3+}$ were produced. The test conducted under above condition with leachate $\mathrm{pH}$ adjustment to 6.0, the COD removal rate obtained was 1\%; while using $\mathrm{FeCl}_{3}$ as coagulant with the same operational condition, much higher COD removal rate of $10 \%$ was achieved. Compared to the COD removal results obtained for chemical coagulation, the removal rates obtained from our test were much lower than expected.

These results confirm the complex nature of the treatment process and the numerous parameters that interact. A different electrode configuration (larger contact area, smaller gap between electrodes, larger number of electrode pairs) or different electrode materials could provide more positive results.

One of the most common problems associated with this process is the formation of a scum layer on the electrodes, especially on the anode (Figure 14). The additional layer increases the resistance of the system which in turn demands more voltage to complete the circuit, resulting in higher electrical power consumption. This situation was observed during the experiments, but due to the relative short duration of the tests, it did not present a significant problem. 

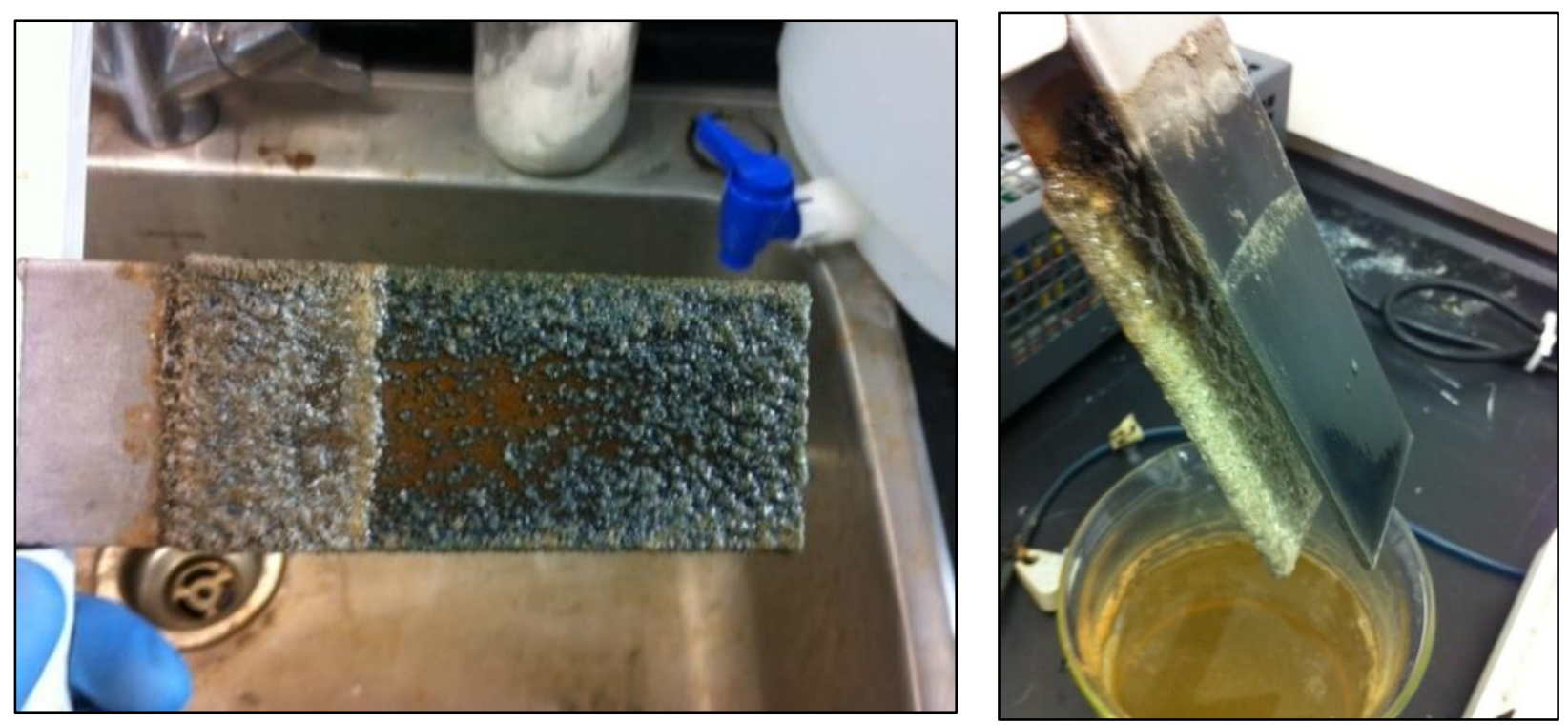

Figure 14. Scum deposits formed on the metal electrodes.

The process also created a foam layer with an average thickness of $1.0 \mathrm{~cm}$. This foam layer was produced by the electro-flotation process carrying low density contaminants to the surface (Figure 15). This layer was persistent even after the 1 hour settling time and as was mentioned before, did present a problem of releasing particles when the sample was been taken for further studies.

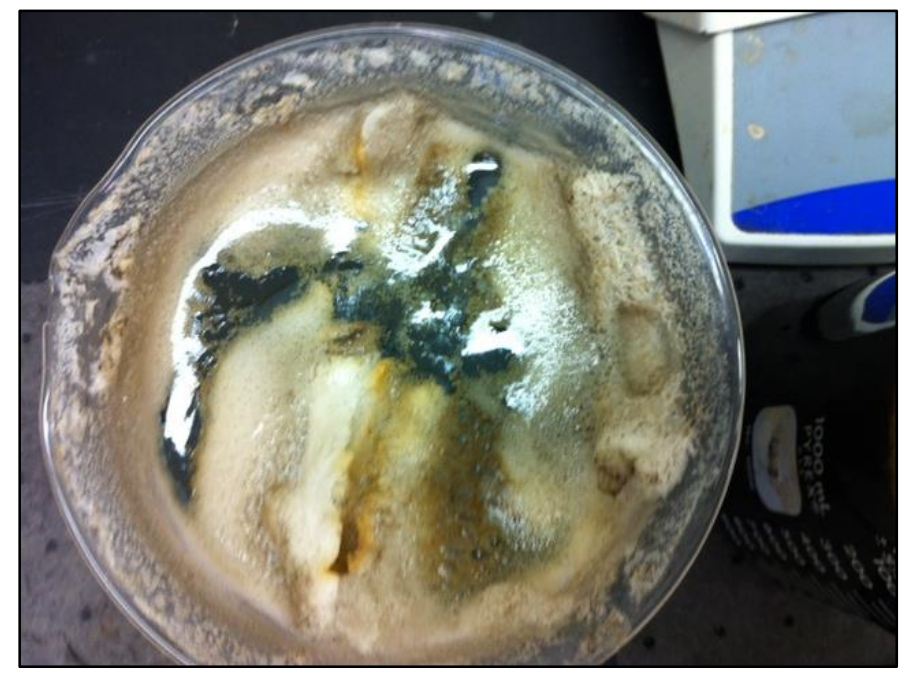

Figure 15. Foam layer due to electro-flotation. Run \#4, $30 \mathrm{~min}, 300 \mathrm{~A} / \mathrm{m}^{2}$. 


\section{Advanced Oxidation with Sodium ferrate}

The stock ferrate solution has a very high $\mathrm{pH}$ value $(\approx 13.0)$. This resulted in the final $\mathrm{pH}$ after treatment for all the cases higher than the initial value. Even reducing the starting $\mathrm{pH}$ to 4.0 did not damper the higher $\mathrm{pH}$ at the end of the treatment. Figure 16 presents the $\mathrm{pH}$ of each of the runs at the different chemical doses.

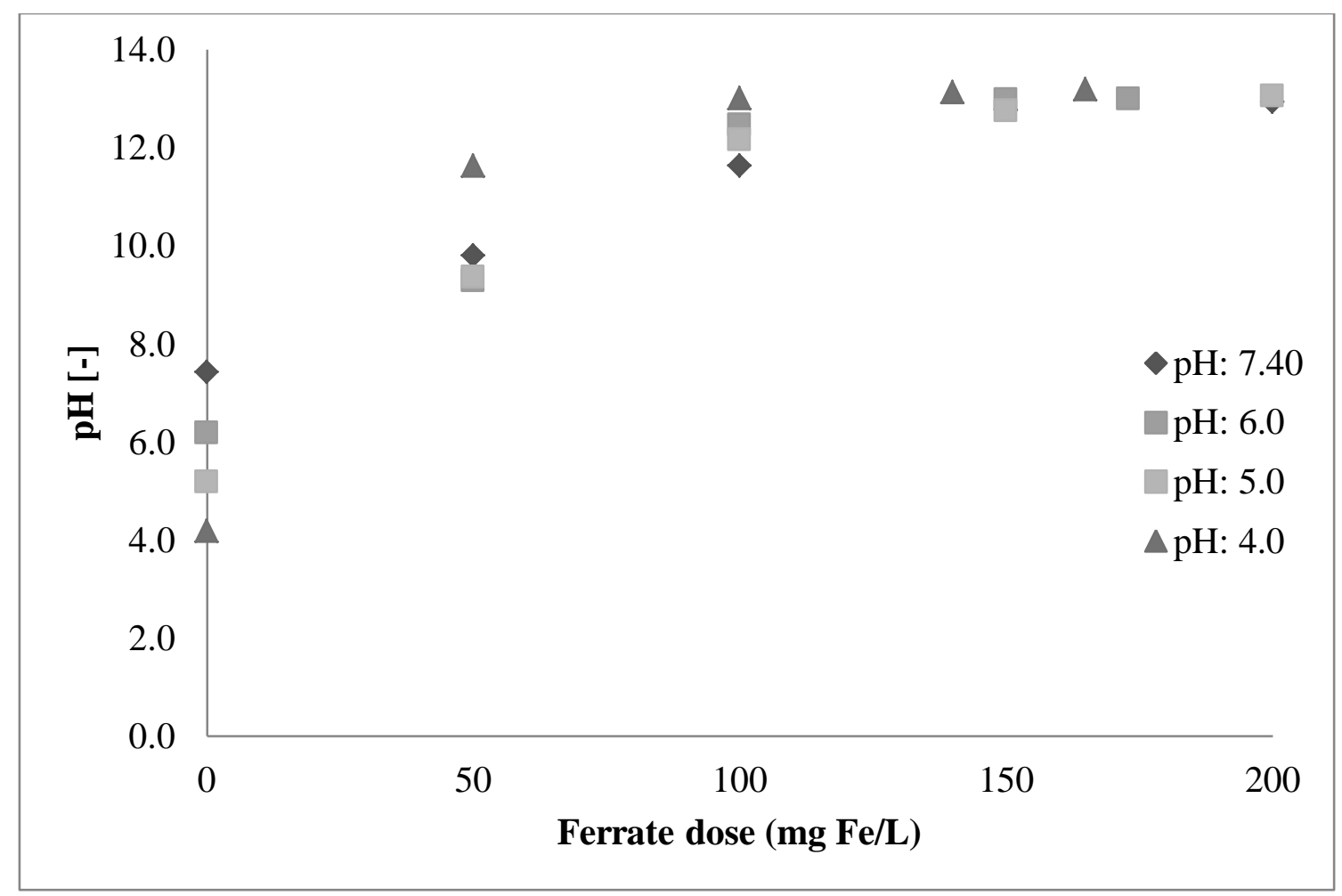

Figure 16. pH values after treatment for the four initial pH values.

The highest COD and ammonia removal rates were $20 \%$ and $16 \%$, respectively. These values were obtained at a pH of 5.0 and a dose of $200 \mathrm{mg} \mathrm{Fe} / \mathrm{L}$, as seen in Figure 18. Under the same operational condition, using $\mathrm{FeCl}_{3}(172 \mathrm{mg} \mathrm{Fe} / \mathrm{L})$ as coagulant provided a much higher COD removal rate of $43 \%$, but a lower ammonia removal rate of $5.7 \%$ (see chemical coagulation). In order to better understand the oxidation of COD by ferrate, DOC concentration was measured (shown in Figure 17). 
As it can be seen that ferrate is effective in the removal of DOC (approximately 64\%); however it is not as effective as $\mathrm{FeCl}_{3}$ in terms of removal of particulate $\mathrm{COD}$ in the leachate. With comparison to chemical coagulation, the higher ammonia removal rate (16\% vs 5.7\%) can be explained by the oxidization of ammonia by Ferrate (VI) which is different mechanism of ammonia removal from coagulation.

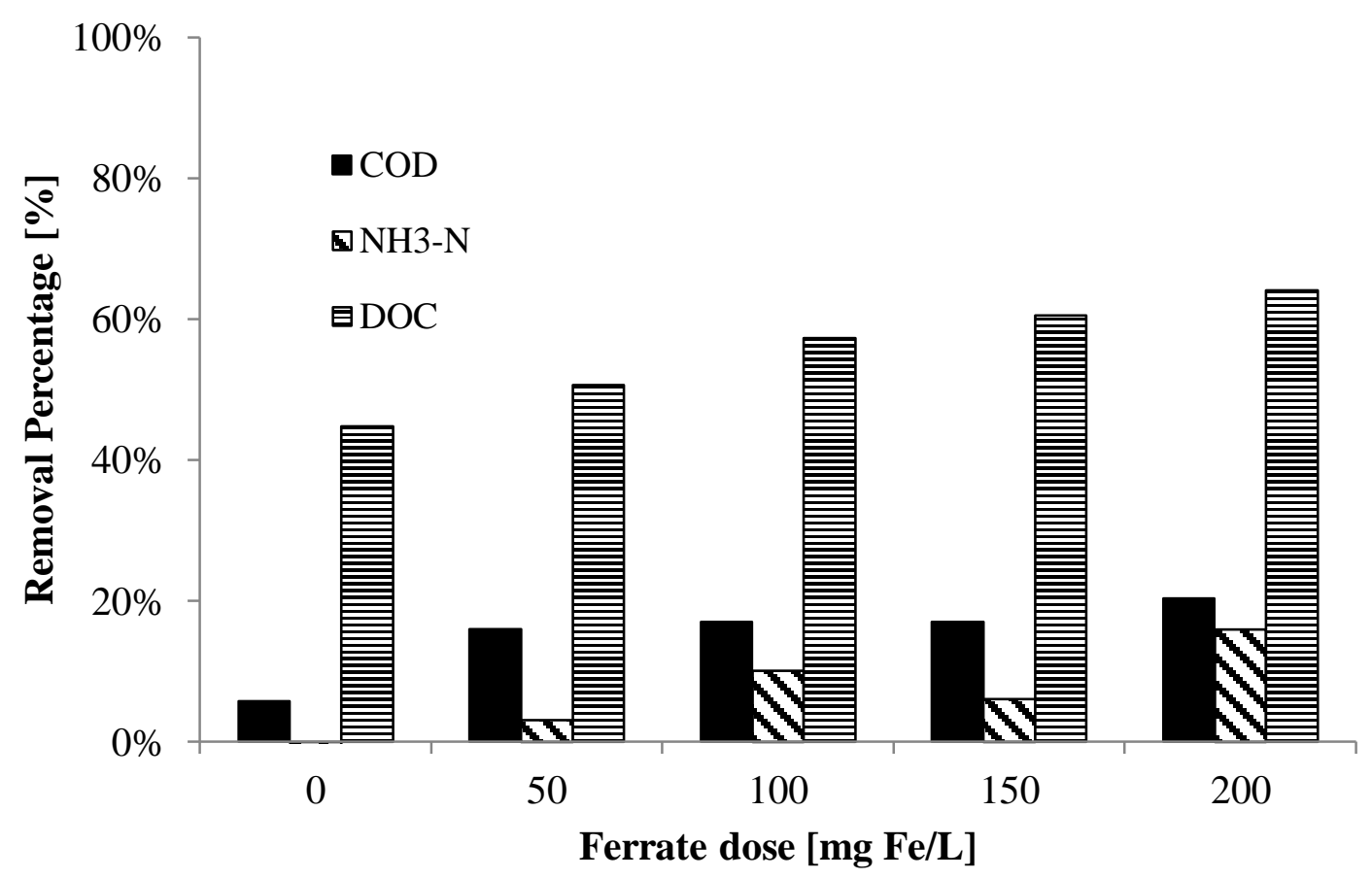

Figure 17. Best results for sodium ferrate pre-treatment at pH 5.0.

The laboratory procedure followed to prepare the sodium ferrate stock solution was delicate and time consuming (can take up to 3 hours). Additionally, the solution must be prepared and used on the same day, as the ferrate compounds are unstable and can degrade in a matter of hours. Once the solution is prepared, a small sample must be analyzed using UV/Vis spectrometry to determine the actual concentration, in order to dose the correct amount to the leachate. 
And finally, due to the need of a buffer solution to help stabilize the sodium ferrate, high dosage volumes of the final solution were needed. All these indicate that for the application of this particular treatment option, on site generation of the chemical would be required, along with the related operational costs.

\section{Pre-treatments Comparison}

Table 3 summarized the optimum operation condition for each pre-treatment option in terms of COD and ammonia removal, obtained from the various testing conditions that were applied to each pre-treatment option.

Table 3. Optimum conditions for the evaluated treatment options

\begin{tabular}{ccccc}
\hline Parameters & Air Stripping & $\begin{array}{c}\text { Chemical } \\
\text { Coagulation }\end{array}$ & $\begin{array}{c}\text { Electro- } \\
\text { coagulation }\end{array}$ & $\begin{array}{c}\text { Sodium } \\
\text { ferrate }\end{array}$ \\
\hline pH & 11.0 & 5.0 & 7.0 & 5.0 \\
Conditions & $\begin{array}{c}\text { Air flow: } \\
1 \mathrm{~L} \text { air / (L*min) }\end{array}$ & $\begin{array}{c}\mathrm{FeCl}_{3} \text { dose: } 172 \\
\mathrm{mg} \mathrm{Fe} / \mathrm{L}\end{array}$ & $\begin{array}{c}\mathrm{CT}: 30 \mathrm{~min} \\
\mathrm{CD}: 300 \mathrm{~A} / \mathrm{m}^{2}\end{array}$ & $\begin{array}{c}\text { Ferrate dose: } \\
200 \mathrm{mg} \mathrm{Fe} / \mathrm{L}\end{array}$ \\
\hline
\end{tabular}

The optimum conditions for each pre-treatment option were evaluated one more time to corroborate the results. For this second round, BOD5 was included to evaluate the pre-treatment options in terms of "biodegradability" improvement. Table 4 presents the removal efficiency values obtained under the optimum conditions of each treatment option. The highest COD removal was obtained with chemical coagulation, while for ammonia removal air stripping was the best option. 
Table 4. Removal efficiency results for the analyzed pre-treatment options

\begin{tabular}{lcccc}
\hline Parameter & Air stripping & $\begin{array}{c}\text { Chemical } \\
\text { coagulation }\end{array}$ & $\begin{array}{c}\text { Electro- } \\
\text { coagulation }\end{array}$ & $\begin{array}{c}\text { Sodium } \\
\text { ferrate }\end{array}$ \\
\hline COD & $19 \%$ & $43 \%$ & $18 \%$ & $20 \%$ \\
TSS & $0 \%$ & $73 \%$ & $70 \%$ & $91 \%$ \\
BOD & $5 \%$ & $36 \%$ & $40 \%$ & $86 \%$ \\
DOC & $1 \%$ & $69 \%$ & $8 \%$ & $64 \%$ \\
NH $_{3}-\mathbf{N}$ & $86 \%$ & $6 \%$ & $0 \%$ & $16 \%$ \\
TP & $22 \%$ & $75 \%$ & $74 \%$ & $61 \%$ \\
\hline
\end{tabular}

\section{Biodegradability Observations}

BOD of the fresh leachate sample was measured at $248 \mathrm{mg} / \mathrm{L}$ from a onetime sample. However, this value is consistent with the average of $245 \mathrm{mg} / \mathrm{L}$ reported by the landfill laboratory report. The BOD/COD ratio was used as a parameter to estimate "biodegradability" before and after each one of the pre-treatment methods - Table 5.

Table 5. BOD/COD ratios for untreated and treated leachate

\begin{tabular}{cccccc}
\hline & Untreated & Air Stripping & $\begin{array}{c}\text { Chemical } \\
\text { Coagulation }\end{array}$ & $\begin{array}{c}\text { Electro- } \\
\text { coagulation }\end{array}$ & $\begin{array}{c}\text { Sodium } \\
\text { ferrate }\end{array}$ \\
\hline BOD/COD & 0.12 & 0.10 & 0.10 & 0.08 & 0.02 \\
\hline
\end{tabular}

The untreated leachate presents a $\mathrm{BOD} / \mathrm{COD}$ ratio of 0.12 , which is considered as low biodegradability. The four treatment options did not show any improvement in terms of increasing the BOD/COD ratio. Even more, for the last 2 treatment options the BOD/COD ratio decreased. Electro-coagulation and sodium ferrate had higher BOD removal compared to COD removal (40\% BOD removal versus 18\% COD removal for electro-coagulation, for example). This shows that the last two treatment options were more efficient targeting and degrading 
biodegradable compounds. This would indicate that these options would be best applied to leachate with a higher BOD concentration.

\section{Odour Strength Assessment}

The odour strength of untreated and pretreated samples was evaluated following the procedures described in Appendix B. The untreated leachate reports a strength between $15>\mathrm{D} / \mathrm{T} \geq 7$. Table 6 presents the results after each one of the treatments. All the options managed to reduce the perceived strength of the leachate odor and chemical coagulation provided the best results.

Table 6. Odor strength results after treatment

\begin{tabular}{lc}
\hline \multicolumn{1}{c}{ Treatment } & Odor strength \\
\hline Untreated & $15>\mathrm{D} / \mathrm{T} \geq 7$ \\
Air stripping & $7>\mathrm{D} / \mathrm{T}>4$ \\
Chemical coagulation & $\mathrm{D} / \mathrm{T}<2$ \\
Electro-coagulation & $7>\mathrm{D} / \mathrm{T}>4$ \\
Sodium ferrate & $7>\mathrm{D} / \mathrm{T}>4$ \\
\hline
\end{tabular}

\section{Combination of Selected Pre-treatments}

Removal efficiency results for Combination 1 (Air stripping first, then chemical coagulation) are presented in Table 7. When the $\mathrm{pH}$ was directly modified at the start of the test (Column A) the removal efficiency presented the highest values. Not modifying the $\mathrm{pH}$ (Column B) or the substitution of ferric chloride for calcium carbonate (Column C) provided zero or little contribution. 
Table 7. Removal efficiency results for Combination 1

\begin{tabular}{|c|c|c|c|}
\hline & \multicolumn{3}{|c|}{ Chemical coagulation } \\
\hline Parameter & $\begin{array}{c}\mathrm{pH} \underset{\mathrm{A}}{\Delta, \mathrm{FeCl}_{3}} \\
\text { (A) }\end{array}$ & $\begin{array}{c}\text { No pH } \Delta, \mathrm{FeCl}_{3} \\
\text { (B) }\end{array}$ & $\begin{array}{c}\text { No pH } \underset{(\mathbf{C})}{\Delta, \mathrm{CaCO}_{3}} \\
\end{array}$ \\
\hline COD & $50 \%$ & $24 \%$ & $23 \%$ \\
\hline TSS & $57 \%$ & $54 \%$ & $51 \%$ \\
\hline BOD $_{5}$ & $14 \%$ & $1 \%$ & $-1 \%$ \\
\hline DOC & $79 \%$ & $19 \%$ & $17 \%$ \\
\hline $\mathrm{NH}_{3}-\mathrm{N}$ & $85 \%$ & $85 \%$ & $85 \%$ \\
\hline TP & $76 \%$ & $67 \%$ & $68 \%$ \\
\hline
\end{tabular}

Combination 2 evaluated the results of treating leachate by chemical coagulation first, then air stripping (Table 8).

Table 8. Removal efficiency results for Combination 2

\begin{tabular}{lcc}
\hline \multicolumn{1}{c}{ Parameter } & $\boldsymbol{p H} \Delta, \mathbf{F e C l}_{3}$ & $\mathbf{N o} \boldsymbol{p H} \Delta, \mathrm{CaCO}_{3}$ \\
& $(\boldsymbol{D})$ & $(\boldsymbol{E})$ \\
\hline COD & $45 \%$ & $10 \%$ \\
TSS & $0 \%$ & $30 \%$ \\
BOD & $13 \%$ & $33 \%$ \\
DOC $_{5}$ & $67 \%$ & $13 \%$ \\
NH $_{3}-\mathrm{N}$ & $83 \%$ & $53 \%$ \\
TP & $74 \%$ & $47 \%$ \\
\hline
\end{tabular}

The results from this test showed that the order of the treatments (either starting with air stripping or with the chemical coagulation) had no significant impact on the result. Both processes provided similar pre-treatment results for the leachate, with COD and ammonia removal rate in the range of $45 \%$ to $50 \%$ and $83 \%$ to $85 \%$, respectively. Additionally, the substitution of ferric chloride for calcium carbonate (Columns $\mathrm{C}$ and E) proved to be less efficient. 


\section{Phase II: Effect of Pre-treated Leachate on Biological System}

\section{Stage 1: Short Term Test (shock load)}

The performance of nitrification was evaluated in a SBR system fed with the mixture of wastewater with leachate with and without pre-treatment. The municipal wastewater presented an average COD concentration of $278 \mathrm{mg} / \mathrm{L}(168 \mathrm{mg} / \mathrm{L}$ standard deviation) and an ammonia concentration of $32 \mathrm{mg} / \mathrm{L}$ (10 mg/L standard deviation). Each cycle consisted of an anaerobic period of $1.5 \mathrm{~h}$ and an aerobic period of $4 \mathrm{~h}$.

Figure 18 present the results when untreated and pre-treated leachate is mixed in with the wastewater at different percentages. Control represents the reactor with only wastewater as influent. Mixing leachate (either pre-treated or untreated) with wastewater at $0.5 \%$ and $1.0 \% \mathrm{v} / \mathrm{v}$ does not produce any significant difference in the ammonia influent concentrations or the system response (Figure 18.a and 18.c). However, when the mixing rate was increased to 5.0\% and $10.0 \% \mathrm{v} / \mathrm{v}$ with untreated leachate (Figure 18.b), it can be seen that the ammonia influent concentration increased 2 to 3 times the value of the control. Additionally, the system was not able to achieve full nitrification in one cycle (ammonia concentrations in the effluent are 3.6 $\mathrm{mg} / \mathrm{L}$ and $20.4 \mathrm{mg} / \mathrm{L}$, respectively). This is suspected to be due to the higher concentration of ammonia in the influent and not a problem with nitrification inhibition, as the rate of nitrification (shown for $5.0 \%$ and $10.0 \%$ as the slope of the curve) is comparable to the rate presented by the control. A longer aeration period would be needed for the full conversion of ammonia at these higher concentrations. 
As shown in Figure 18.d, the pre-treatment of leachate lowered the ammonia in the influent, therefore, allowing full nitrification under the same operational condition. It was concluded that pre-treatment of leachate is necessary when the mixing ratio of leachate with wastewater is higher $(5.0 \%$ to $10.0 \%)$, to assure the performance of nitrification at the wastewater treatment plant.

In terms of soluble COD removal, systems fed with the pre-treated leachate also provide a better removal than the ones with untreated leachate. The effluent sCOD concentration after the 5.5 hour operation with the pre-treated leachate in all cases was lower than $50 \mathrm{mg} / \mathrm{L}$, which is very close to the control values (Figures 20.c and 20.d). However, for the ones with untreated leachate, the sCOD in the effluent was in the range of 50 to $92 \mathrm{mg} / \mathrm{L}$ (Figures 19.a and 19.b).

The pre-treatment methods selected were previously proven to reduce soluble COD and ammonia concentrations on the leachate. Without the pre-treatment, mixing the leachate with the municipal wastewater increased the influent values of sCOD and ammonia to a point where removal by biological means was not achievable in the time provided by the BNR system. 


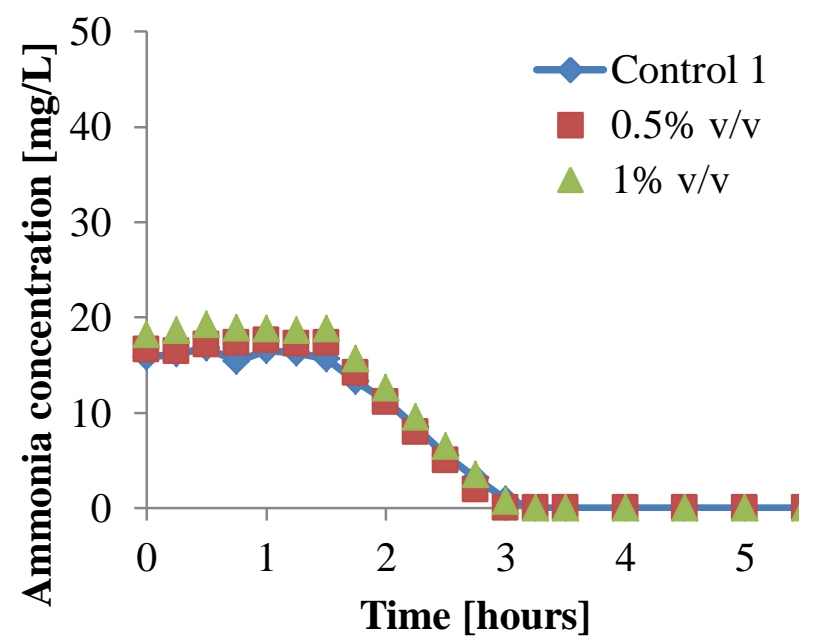

18.a

Untreated leachate

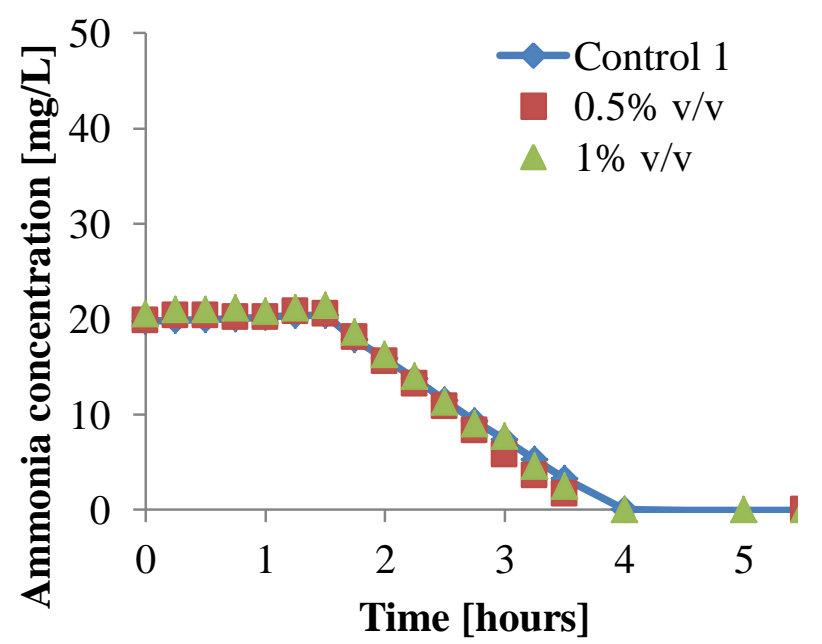

18.c

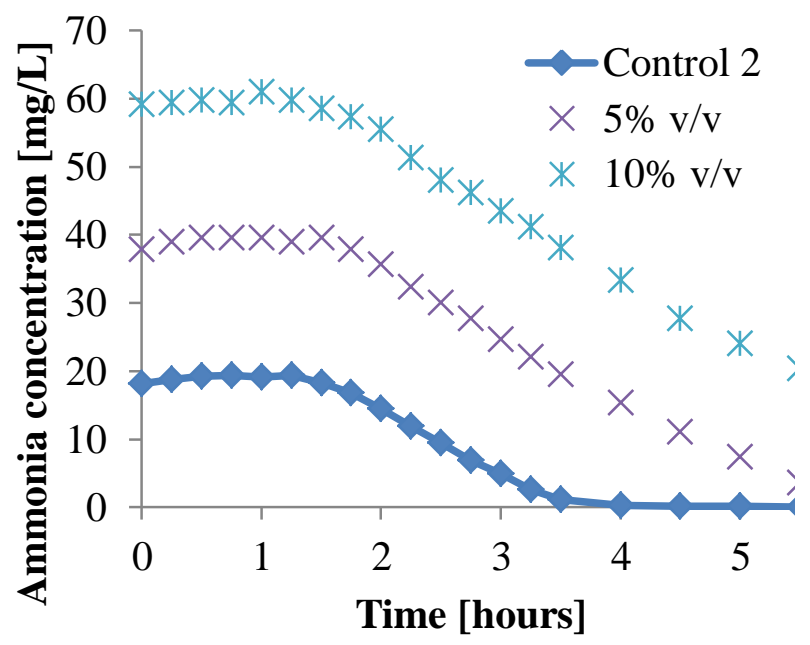

18.b

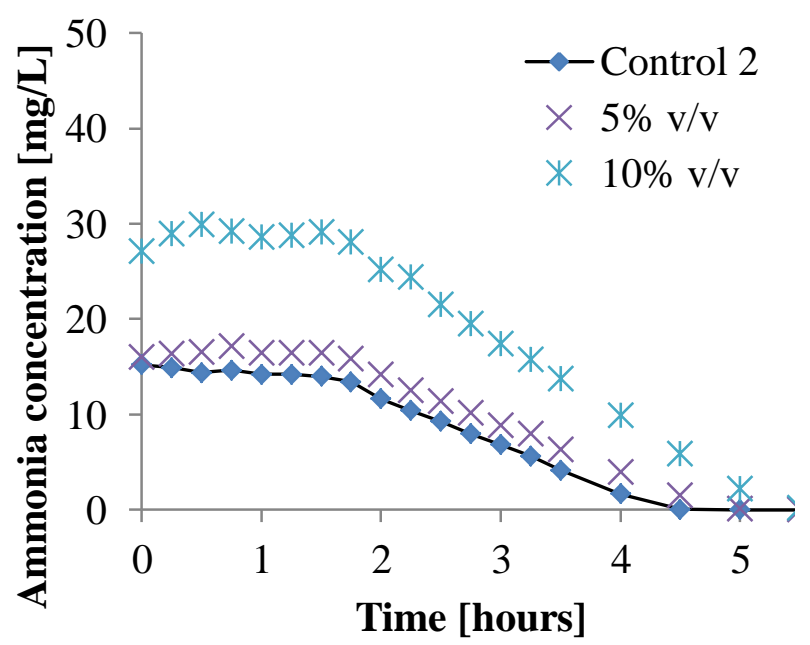

18.d

Pre-treated leachate

Figure 18. Impact of untreated and pre-treated leachate on ammonia degradation at different proportion of added leachate 


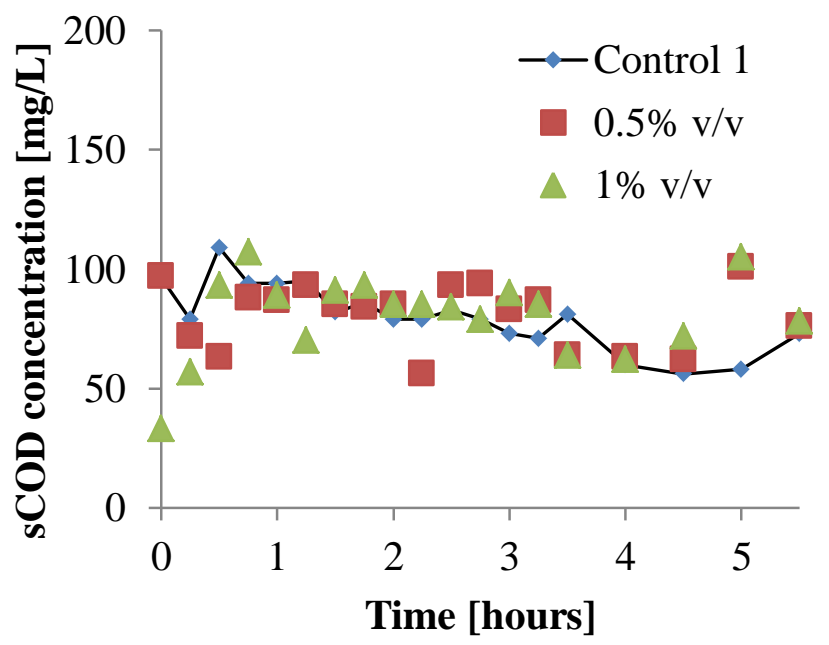

19.a

\section{Untreated leachate}

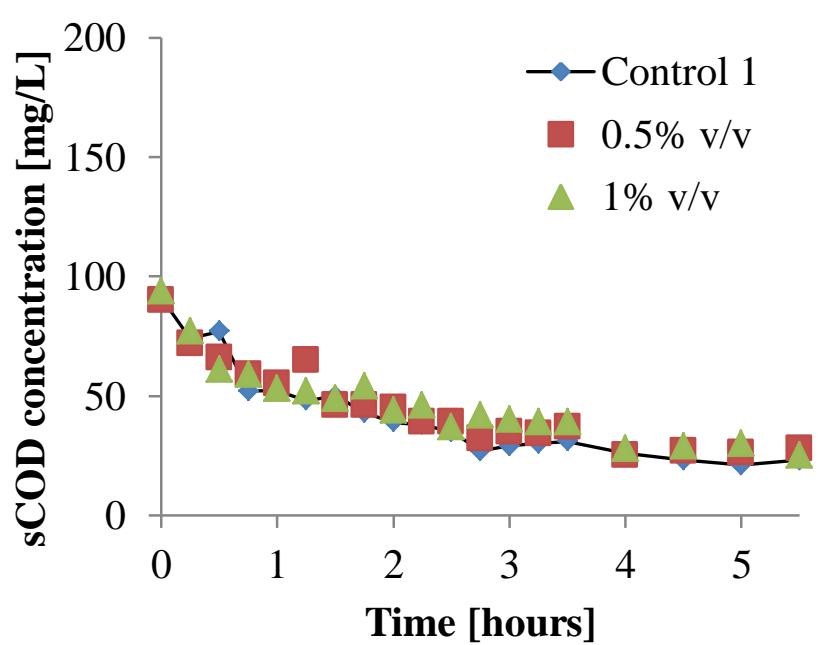

19.c

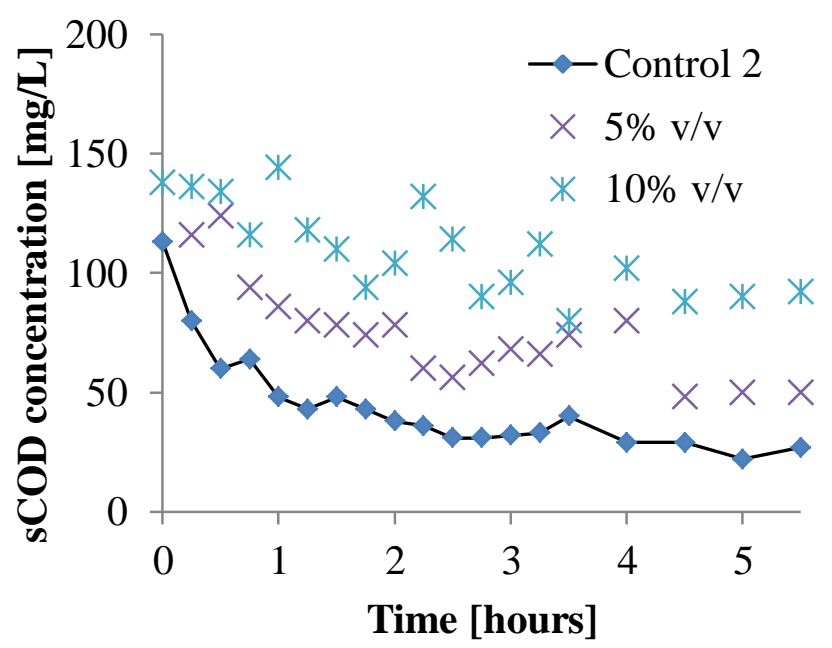

19.b

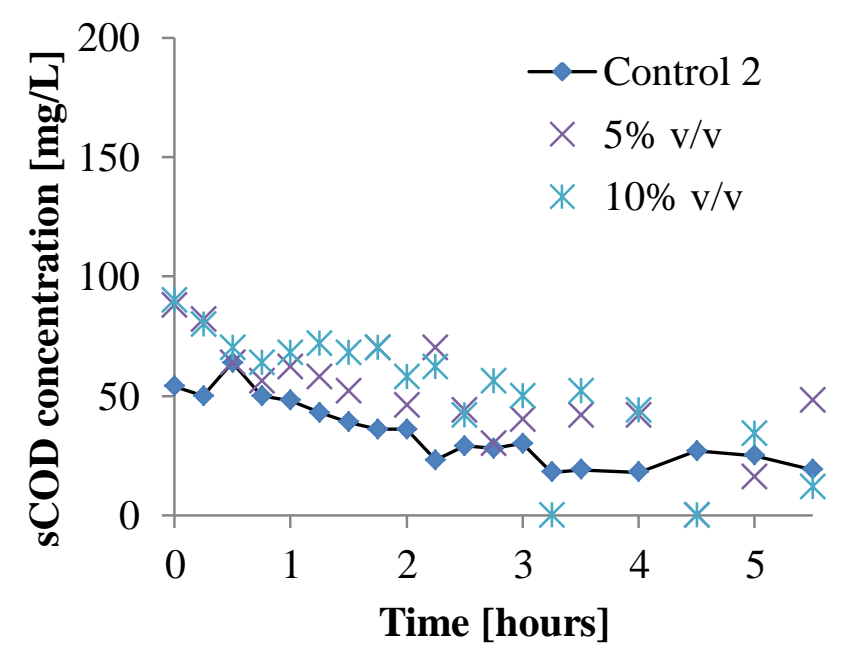

19.d

Pre-treated leachate

Figure 19. Impact of untreated and pre-treated leachate on soluble COD degradation at different proportion of added leachate 


\section{Stage 2: Long Term Test}

In the Second stage the effect of continuous mixing the leachate with the wastewater was studied. Figure 20 shows the set up used. Only air stripping was selected as pre-treatment for this final stage.

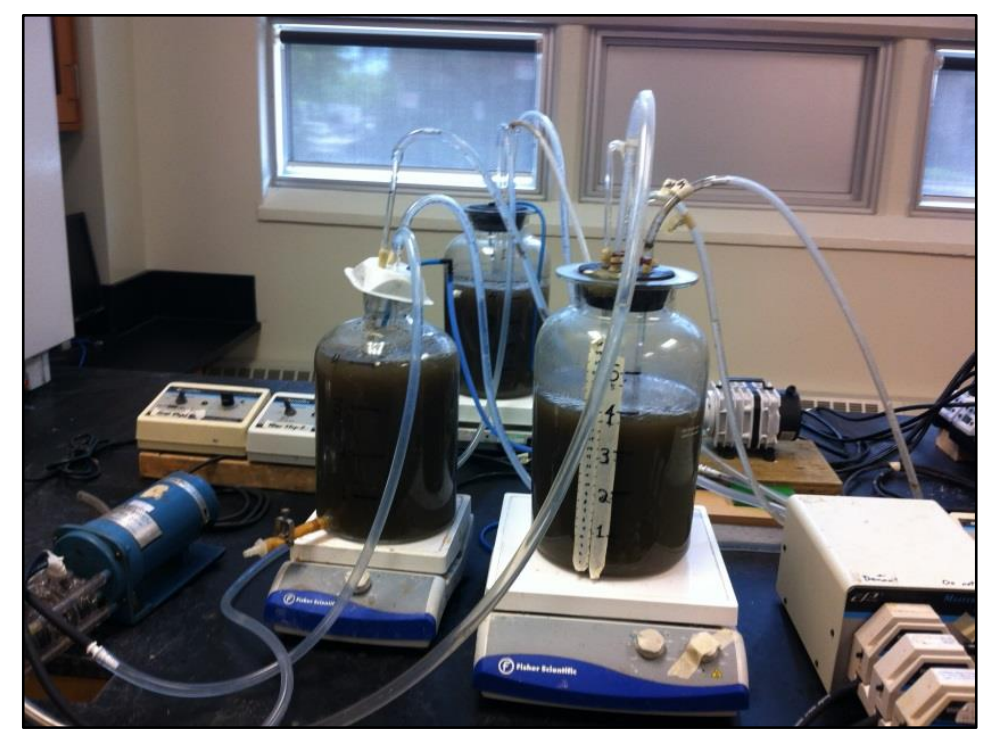

Figure 20. Long term biological treatment test set up.

Monitoring started after the reactors were seeded with biomass, and continued for 20 days during the acclimation period. COD and ammonia effluent values, as well as TSS concentration in the reactors, were the parameters used to determine if stable conditions were met. COD effluent concentration was maintained under $27 \mathrm{mg} / \mathrm{L}$ and ammonia effluent concentration at $0 \mathrm{mg} / \mathrm{L}$ for the three reactors during this acclimation period (Figure 21).

The TSS concentration during the $2.5 \%$ mixing experiment ranged between 1.45 and $2.65 \mathrm{~g} / \mathrm{L}$ for the Control, between 1.47 and $2.33 \mathrm{~g} / \mathrm{L}$ for the reactor fed pre-treated leachate and sewage and between 1.58 and $2.40 \mathrm{~g} / \mathrm{L}$ for the reactor fed untreated leachate mixed with wastewater. The 
concentration values for the $5.0 \%$ mixing experiment ranged between 1.64 and $3.60 \mathrm{~g} / \mathrm{L}$ for the Control, between 0.70 and $1.73 \mathrm{~g} / \mathrm{L}$ for the reactor fed pre-treated leachate and between 1.05 and $2.10 \mathrm{~g} / \mathrm{L}$ for the reactor fed untreated leachate.

Figure 21 presents the values of total COD for the three reactors during the acclimation period and the two sets of experiments mentioned previously. At a mixing rate of $2.5 \%$ the effluent total COD for the Control, the reactor fed pre-treated leachate mixed with wastewater and the reactor fed untreated leachate with sewage reported average values of $30 \mathrm{mg} / \mathrm{L}, 46 \mathrm{mg} / \mathrm{L}$ and $51 \mathrm{mg} / \mathrm{L}$, respectively. When the mixing rate was increased to $5.0 \%$ the average values reported were 49 $\mathrm{mg} / \mathrm{L}, 96 \mathrm{mg} / \mathrm{L}$ and $89 \mathrm{mg} / \mathrm{L}$ for the reactors in the same order. The increase was expected with the higher percentage of mixed leachate.

The two reactors fed leachate and wastewater (pre-treated and untreated) presented similar results, which is expected as the pre-treatment (air stripping only) did not focus on COD removal. 


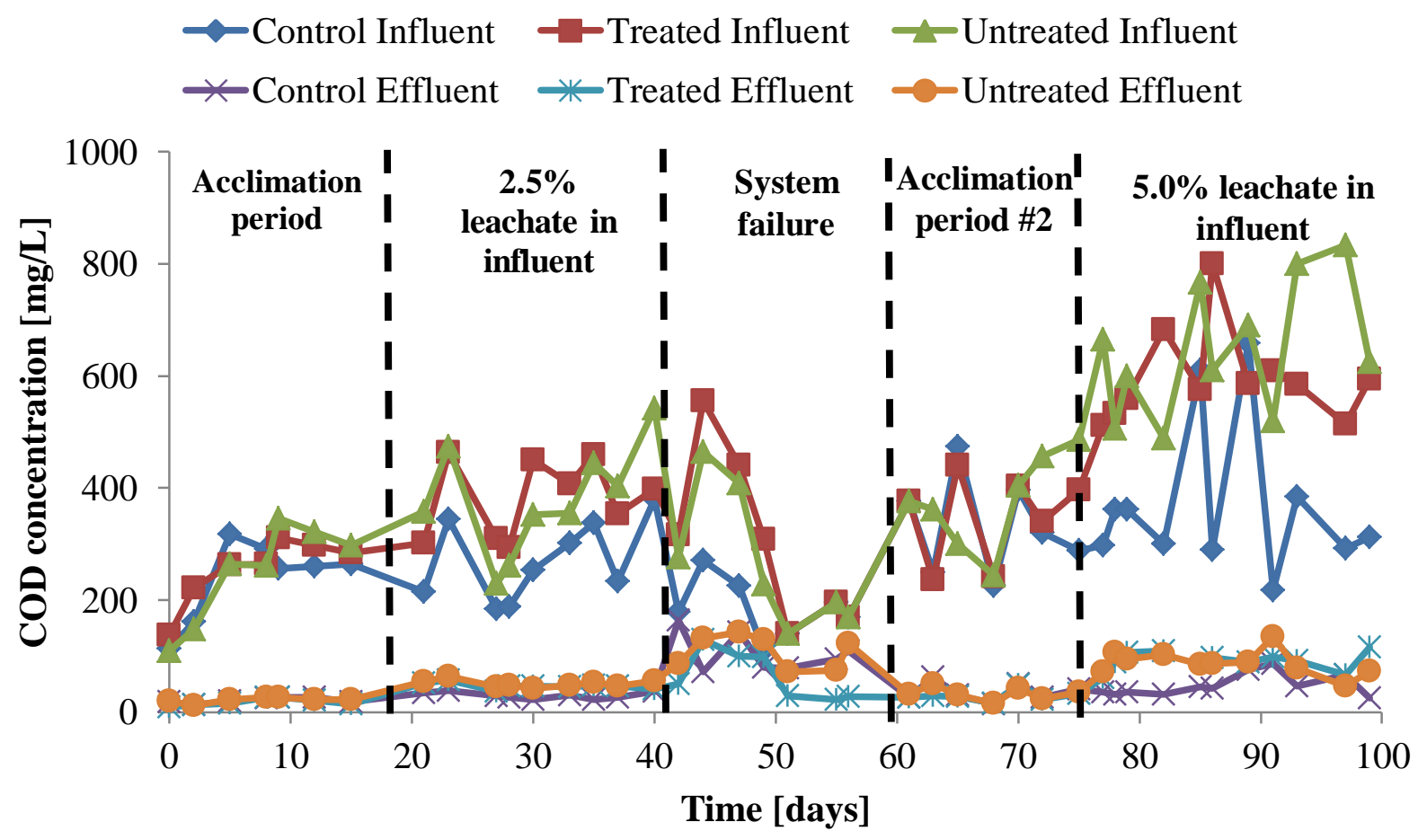

Figure 21. Total COD feed and effluent for Control, Treated and Untreated reactors during complete testing period

Taking a closer look at the response during a single cycle, Figure 22 shows the depletion of soluble COD from time 0 to 5.5 hours later. All of the reactors presented a decrease in SCOD as time advanced; however the reactor fed with pre-treated leachate present overall higher values than the reactor with untreated leachate. Even though air stripping as pre-treatment is not focused on COD removal, it should not increase the values compared to untreated leachate. 


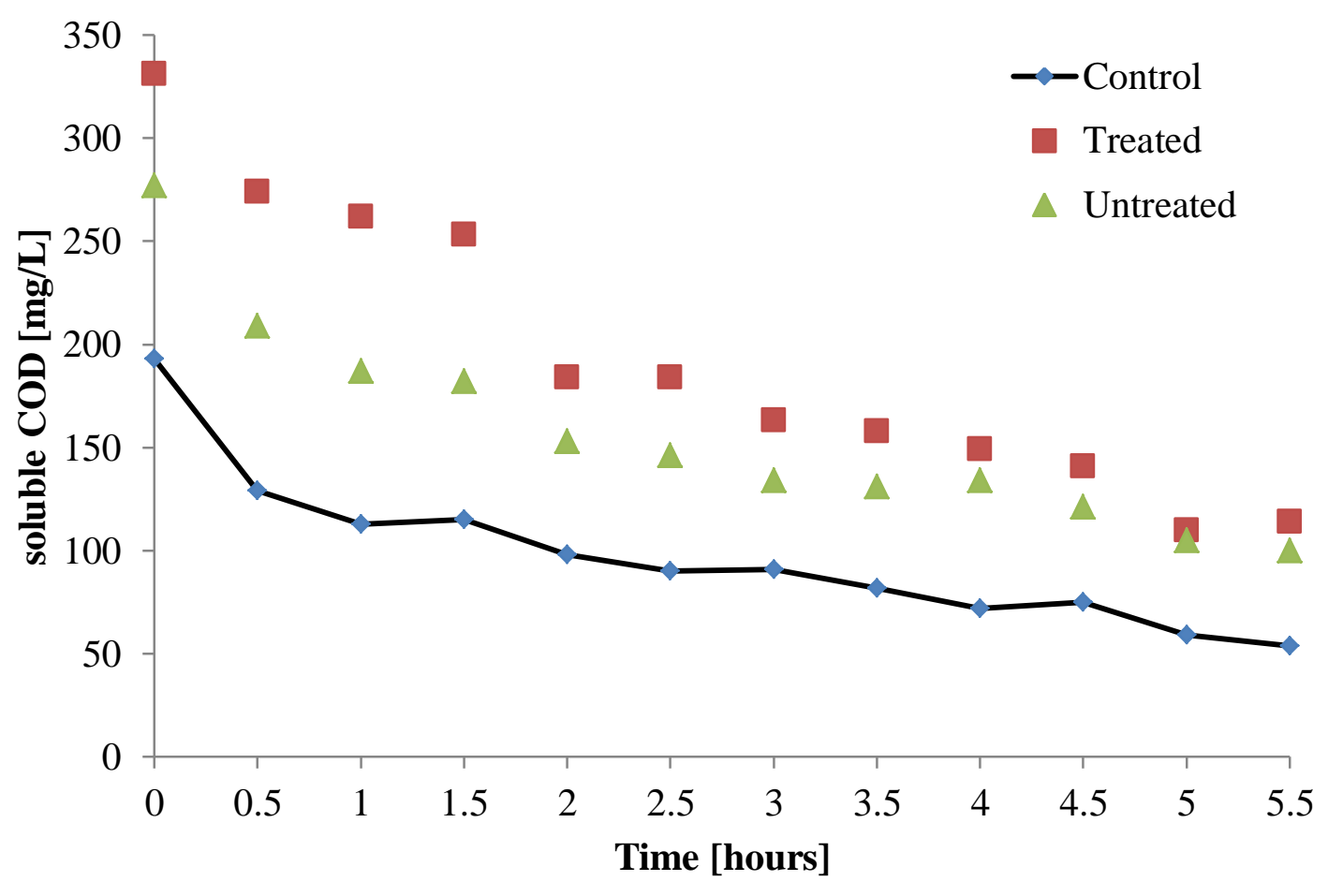

Figure 22. Soluble COD degradation during one SBR cycle.

In terms of ammonia removal, the system provided a more distinctive set of results. Figure 23 shows that for test of the mixing rate of $2.5 \%$ (days 20 to 42 ) the average ammonia concentration in the influent of the Control, the reactor fed pre-treated leachate and wastewater and the reactor fed untreated leachate and wastewater was $35 \mathrm{mg} / \mathrm{L}, 43 \mathrm{mg} / \mathrm{L}$ and $53 \mathrm{mg} / \mathrm{L}$, respectively. The three reactors were able to fully remove the incoming ammonia, resulting in an effluent ammonia concentration of approximately $0 \mathrm{mg} / \mathrm{L}$. A similar pattern was observed at a mixing rate of $5.0 \%$ (days 77 to 99), where the influent ammonia values corresponded to $38 \mathrm{mg} / \mathrm{L}, 37 \mathrm{mg} / \mathrm{L}$ and 70 $\mathrm{mg} / \mathrm{L}$ for the Control, the reactor fed pre-treated leachate and wastewater and the reactor fed untreated leachate and wastewater. The effluent ammonia concentration in all the reactors were below the detection limits (lower than $0.1 \mathrm{mg} / \mathrm{L}$ ), indicating that the biomass in each of the reactors was able to adapt to the higher concentration of ammonia in the influent. 


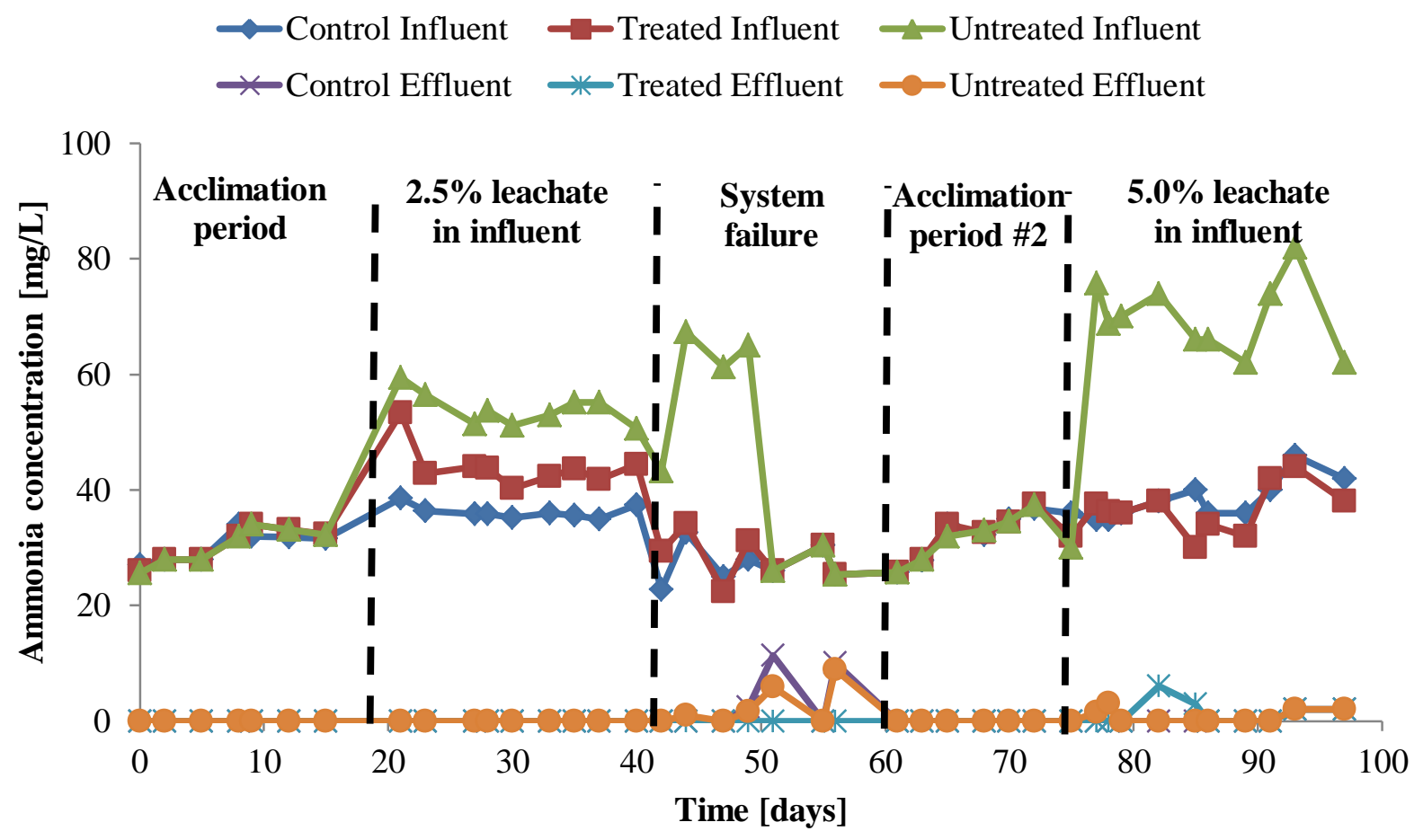

Figure 23. Ammonia feed and effluent for Control, Treated and Untreated reactors.

Looking at the results from the kinetics tests, the ammonia concentration values at time 0 for the reactor with the pre-treated leachate were very similar to that of the Control reactor. For the reactor with the untreated leachate, the initial concentration was twice as high. However, all reactors achieved full nitrification during the 5.5 hours of treatment (Figures 24). The slope of degradation of ammonia is steeper for the reactor with untreated leachate, suggesting that the biomass has acclimated to these conditions. The control reactor presented an ammonia consumption rate of $0.002 \mathrm{~g} \mathrm{NH}_{3}-\mathrm{N} / \mathrm{g} \mathrm{VSS} / \mathrm{h}$, while the reactor fed pre-treated leachate with sewage a rate of $0.003 \mathrm{~g} \mathrm{NH}_{3}-\mathrm{N} / \mathrm{g} \mathrm{VSS} / \mathrm{h}$ and the reactor fed untreated leachate a rate of $0.006 \mathrm{~g}$ $\mathrm{NH}_{3}-\mathrm{N} / \mathrm{g}$ VSS/h. The long term acclimation to higher concentrations of leachate allowed for the biomass to adjust and provide full ammonia degradation. 
Compared to the results observed for the short term test (shock loads), the ammonia removal rate for the reactor fed with untreated leachate is almost the same $\left(0.007 \mathrm{~g} \mathrm{NH}_{3}-\mathrm{N} / \mathrm{g} \mathrm{VSS} / \mathrm{h}\right)$.

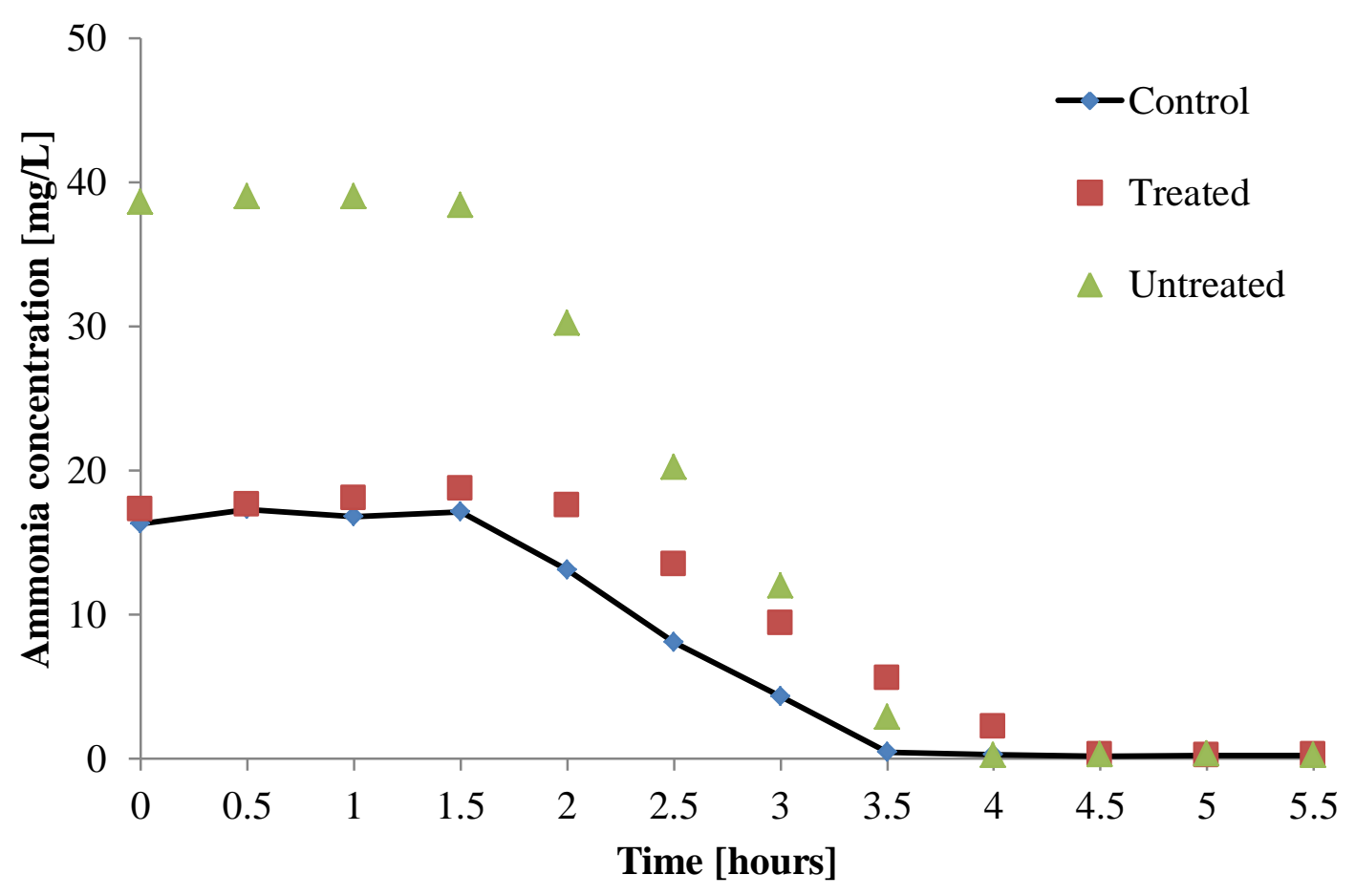

Figure 24. Ammonia degradation during one SBR cycle.

In terms of NOx, an initial concentration was measured every time at the beginning of the cycle. This remnant is left off from the previous cycle, only slightly reduced from the end point of the last cycle due to the decanting process. During the $1.5 \mathrm{~h}$ anaerobic/anoxic period the NOx is removed by denitrifiers (denitrification) as they utilize the NOx as an electron donor while degrading sCOD. In the case of the reactor fed pre-treated leachate, the remnant from the previous cycle is low, allowing for the NOx to be fully consumed. For the Control and the reactor fed untreated leachate, the initial concentration of NOx is higher and the denitrifiers run out of time before consuming it. 
As soon as the aeration starts (after $1.5 \mathrm{~h}$ ), the ammonia gets degraded and NOx is produced. This process stops as the bulk of ammonia is completely consumed (around 4.0 hours after time 0) and the NOx concentration stabilizes (Figure 25).

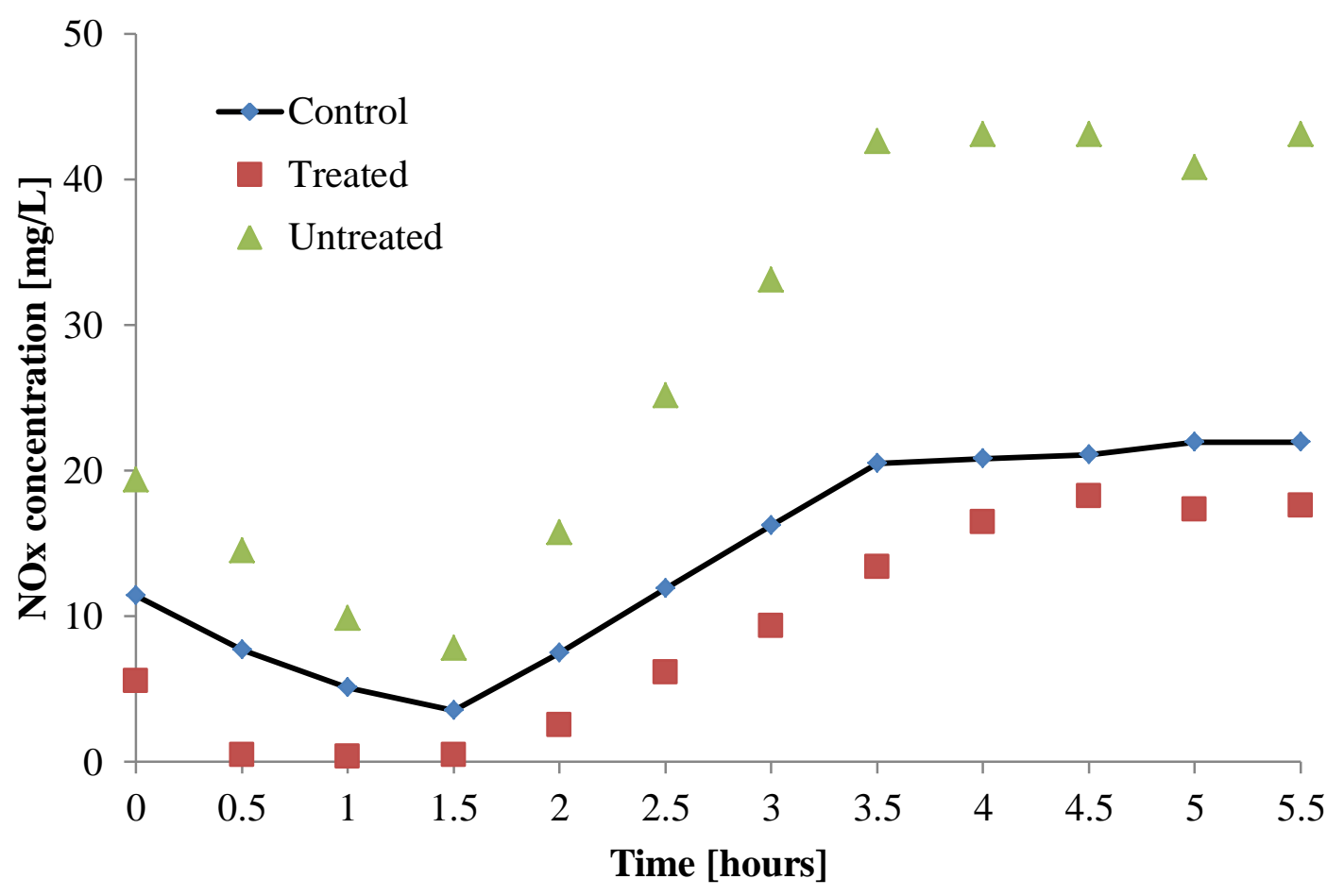

Figure 25. NOx degradation during one SBR cycle.

Phosphorus also presents a typical response from an SBR system with anaerobic and aerobic phases. The leachate in the two mixed reactors provides a higher concentration of sCOD that can be used by Phosphorus Accumulating Organisms (PAO's), increasing the release of phosphorus into the system during the anaerobic phase. As aeration starts the phosphorus concentration decreases again until the cycle stops - See Figure 26. 


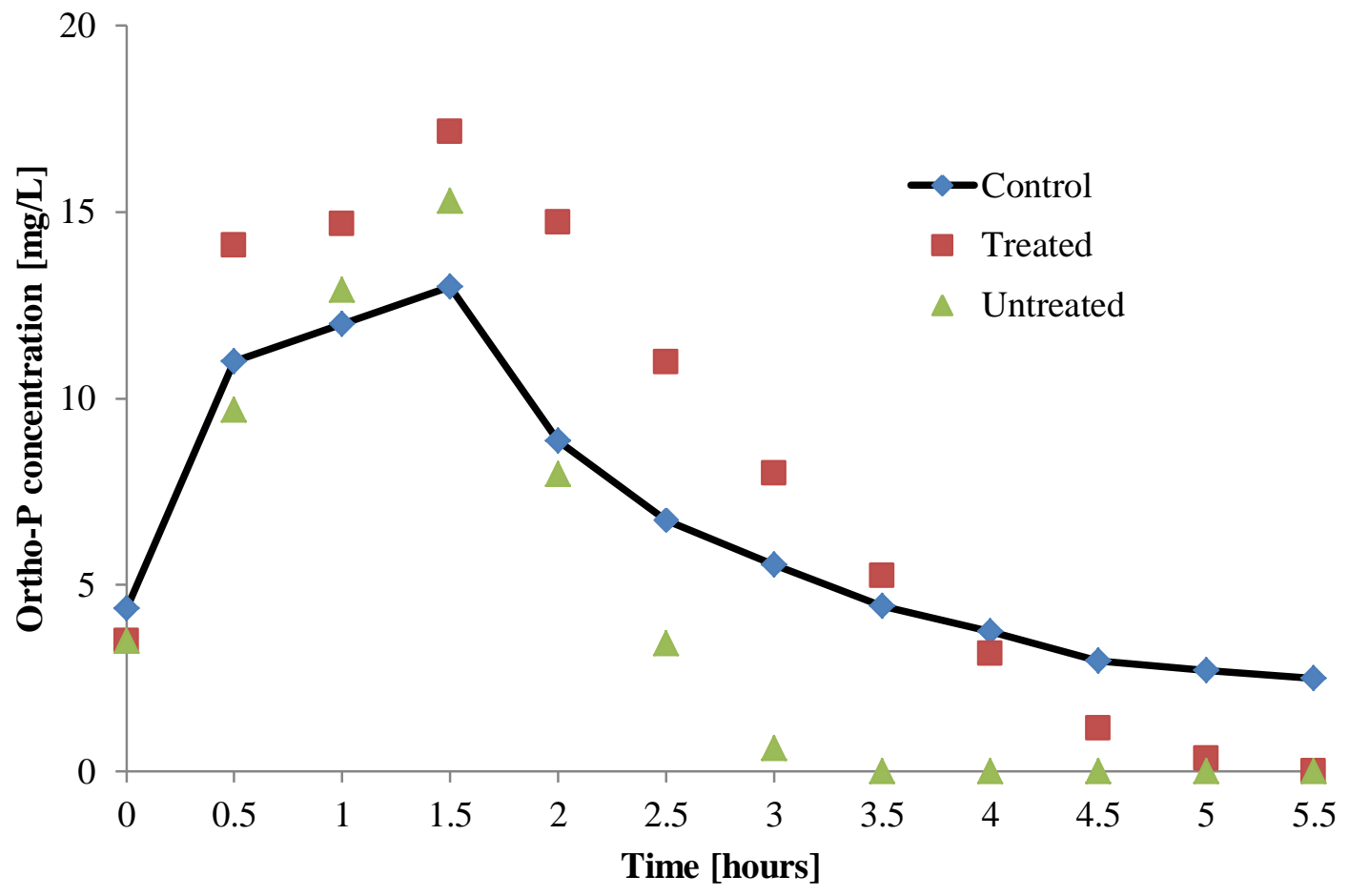

Figure 26. Phosphorus degradation during one SBR cycle. 


\section{CHAPTER 4. CONCLUSIONS}

- In Phase I, four methods of leachate pre-treatment were evaluated to determine the most efficient procedure in terms of COD and ammonia removal: air stripping, chemical coagulation, electro-coagulation and oxidation with sodium ferrate. Chemical coagulation provided the overall best COD removal rate at $43 \%$, while air stripping provided an ammonia removal rate of $86 \%$, superior to the results from the other pre-treatments for this compound. Chemical coagulation reduces COD by destabilizing the electric charges of colloidal particles and removing said particles by precipitation, co-precipitation (sweeping effect) and/or filtration. On the other hand, air stripping relies on the desorption of ammonia from the liquid by providing the right conditions $(\mathrm{pH}$, temperature, contact surface area, etc.) to favor the release of the gas.

- The idea behind electro-coagulation is to provide the same iron based coagulant (as chemical coagulation) without the additional compounds, to minimize sludge production and costs. However, a precise set of parameters are needed to optimize the treatment to a specific leachate. To determine these conditions for the pre-treatment of leachate from BRRMF requires future research. In the case of advanced oxidation with sodium ferrate, the compound was theorized to degrade recalcitrant compounds thus lowering the COD and providing a more biodegradable leachate. The long and complicated procedure to prepare and dose the right amount of sodium ferrate made the pre-treatment not efficient for the objectives of this research. 
- The optimum conditions for chemical coagulation (dosage of $172 \mathrm{mg} \mathrm{Fe} / \mathrm{L}$ at a $\mathrm{pH}$ of 5.0) are comparable to the conditions reported by (Li et al., 2010; Marañón et al., 2008). However, a lower COD removal rate was achieved in this experiment. In the case of air stripping, the conditions found in this research as optimum in terms of ammonia removal were similar to the ones reported by (Cotman and Gotvajn, 2010; Guo et al., 2010) and (Abood et al., 2013), except for the longer duration (48 hours) needed to achieve ammonia removal rates over $85 \%$.

- Pre-treating leachate with a combination of air stripping and chemical coagulation was shown to effectively reduce ammonia (83-85\% removal) and COD (45-50\% removal) from the leachate. The order in which the methods were applied did not affect the overall efficiency of the combined treatment.

- For Phase II, the effect of untreated and pre-treated leachate blended with sewage was evaluated by the response of the biological nutrient removal SBR bench-scale system. This second phase was divided into two stages: short term test (shock load) and long term test.

- Mixing the leachate with or without pre-treatment with municipal sewage at low concentrations $(0.5 \%-1.0 \% \mathrm{v} / \mathrm{v})$ does not produce any significant difference in terms of soluble COD or ammonia influent concentrations, and therefore the response of the system is comparable to the response from the controls fed only wastewater. 
- However, when the untreated leachate mix rate was increased $(5.0 \%$ and $10.0 \% \mathrm{v} / \mathrm{v})$ the ammonia influent concentration doubled or tripled, respectively. Soluble COD influent and effluent concentrations increased as well. Under these conditions the BNR system was not able to achieve full nitrification during one cycle. No nitrification inhibition is suspected as the rate of ammonia removal is similar to that of the controls. The pretreatment of leachate lowered the ammonia in the influent, therefore, allowing again for full nitrification.

- For the long term test, the effect of continuous mixing the leachate with wastewater as feed was studied. One reactor was only fed wastewater blended with untreated leachate and the other one fed wastewater blended with pretreated leachate (air stripping alone). The third one was left as Control, fed only sewage. The mixing percentages used were $2.5 \%$ and $5.0 \%$ by volume. At a mixing rate of $2.5 \%$ the Control, the reactor fed pretreated leachate and the reactor fed untreated leachate reported average effluent total COD values of $30 \mathrm{mg} / \mathrm{L}, 46 \mathrm{mg} / \mathrm{L}$ and $51 \mathrm{mg} / \mathrm{L}$, respectively. When the mixing rate was increased to $5.0 \%$ the average values reported were $49 \mathrm{mg} / \mathrm{L}, 96 \mathrm{mg} / \mathrm{L}$ and $89 \mathrm{mg} / \mathrm{L}$ in the same order.

- In terms of ammonia removal, for the mixing rate of $2.5 \%$ the influent values for the Control, the reactor fed pre-treated leachate and the reactor fed untreated leachate reported average values of $35 \mathrm{mg} / \mathrm{L}, 43 \mathrm{mg} / \mathrm{L}$ and $53 \mathrm{mg} / \mathrm{L}$, respectively. At these values, the three systems were able to fully degrade the incoming ammonia within the 5.5 hours of treatment, providing an effluent of $0 \mathrm{mg} / \mathrm{L}$ in all the cases. At a mixing rate of $5.0 \%$ the influent values corresponded to $38 \mathrm{mg} / \mathrm{L}, 37 \mathrm{mg} / \mathrm{L}$ and $70 \mathrm{mg} / \mathrm{L}$ for the Control, the 
reactor fed pre-treated leachate and the reactor fed untreated leachate, respectively. The effluent values in this case were also mostly $0 \mathrm{mg} / \mathrm{L}$, with just a couple of values at 2 $\mathrm{mg} / \mathrm{L}$.

- The slope of degradation of ammonia is steeper for the reactor with untreated leachate, suggesting that the biomass has acclimated. The control reactor presented an ammonia consumption rate of $0.002 \mathrm{~g} \mathrm{NH}_{3}-\mathrm{N} / \mathrm{g} \mathrm{VSS} / \mathrm{h}$, while the reactor fed pre-treated leachate with sewage a rate of $0.003 \mathrm{~g} \mathrm{NH}_{3}-\mathrm{N} / \mathrm{g} \mathrm{VSS} / \mathrm{h}$ and the reactor fed untreated leachate a rate of $0.006 \mathrm{~g} \mathrm{NH}_{3}-\mathrm{N} / \mathrm{g} \mathrm{VSS} / \mathrm{h}$.

- At both mixing conditions, regardless of the high concentration of ammonia present in the untreated leachate, all the three reactors were able to fully remove the ammonia in the influent. This suggested that the dilution factor played an important role in lowering the ammonia concentration in the influent.

- The kinetic study in the long term tests showed that all the reactors achieved full nitrification within the treatment cycle time. The reactor fed with untreated leachate and wastewater had the highest ammonia removal rate. This demonstrated that the biomass was able to adapt to the higher ammonia influent concentration.

- As an overall conclusion, the results suggested that pre-treatment of leachate may not be necessary if the load of leachate is much smaller than the municipal wastewater load at a wastewater treatment plant. It is important to differentiate that is the ratio of load (connecting flow and strength) of leachate to the load of wastewater what determines the effect in the influent concentrations entering the wastewater treatment plant. Leachate by 
nature may fluctuate from season to season and from well to well in the same landfill, so in order to avoid a sudden shock load into the plant, a equalization tank may be utilized to properly mix and attenuate the differences between the leachate and the wastewater. 


\section{CHAPTER 5. ENGINEERING SIGNIFICANCE}

Based on the ratios of leachate to wastewater flows expected at the SEWPCC if co-treatment is implemented in this plant in the future, the results presented in this research suggest that pretreatment of leachate may not be necessary.

However, as is indicated in the conclusions, it must be understand that is the ratio of loads what determines the effect in the influent concentrations entering the wastewater treatment plant. As leachate concentrations may vary seasonally and/or from different locations within the same landfill, an equalization tank prior to entering the treatment plant would allow for the proper mixing of leachate and wastewater stabilizing the influent load. 


\section{REFERENCES}

Abood, A.R., Bao, J., Abudi, Z.N., Zheng, D., Gao, C., 2013. Pretreatment of nonbiodegradable landfill leachate by air stripping coupled with agitation as ammonia stripping and coagulation-flocculation processes. Clean Technol. Environ. Policy 15, 1069-1076.

Amokrane, A., Comel, C., Veron, J., 1997. Landfill leachates pretreatment by coagulationflocculation. Water Res. 31, 2775 - 2782.

ASTM E544-10, 2010. Standard Practices for Referencing Suprathreshold Odor Intensity. American Society for Testing and Materials, West Conshohocken, PA. U.S.A.

ASTM E679-04, 2011. Standard Practice for Determination of Odor and Taste Thresholds By a Forced- Choice Ascending Concentration Series Method of Limits. American Society for Testing and Materials, West Conshohocken, PA. U.S.A.

ASTM Standard D2035, 2013. Standard Practice for Coagulation-Flocculation Jar Test of Water. ASTM International, West Conshohocken, PA.

Batarseh, E.S., Reinhart, D.R., Daly, L., 2007. Liquid Sodium Ferrate and Fenton's Reagent for Treatment of Mature Landfill Leachate. J. Environ. Eng. 133, 1042-1050.

Cheung, K.C., Chu, L.M., Wong, M.H., 1997. Ammonia stripping as a pretreatment for landfill leachate. Water. Air. Soil Pollut. 94, 209-221.

Collivignarelli, C., Bertanza, G., Baldi, M., Avezzu, F., 1998. Ammonia stripping from MSW landfill leachate in bubble reactors: process modeling and optimization. Waste Manag. Res. $16,455-466$.

Contreras, J., Villarroel, M., Navia, R., Teutli, M., 2009. Treating landfill leachate by electrocoagulation. Waste Manag. Res. 27, 534-541.

Cotman, M., Gotvajn, A.Z., 2010. Comparison of different physico-chemical methods for the removal of toxicants from landfill leachate. J. Hazard. Mater. 178, 298-305.

Eaton, A., Rice, E., Baird, R. (Eds.), 2012. Standard Methods for the Examination of Water and Wastewater, 22nd ed. American Public Health Association (APHA), American Water Works Association (AWWA), Water Environment Federation (WEF).

Guo, J.-S., Abbas, A., Chen, Y.-P., Liu, Z.-P., Fang, F., Chen, P., 2010. Treatment of landfill leachate using a combined stripping, Fenton, SBR, and coagulation process. J. Hazard. Mater. 178, 699-705.

Ilhan, F., Kurt, U., Apaydin, O., Gonullu, M., 2008. Treatment of leachate by electrocoagulation using aluminum and iron electrodes. J. Hazard. Mater.

Jiang, J.-Q., 2007. Research progress in the use of ferrate(VI) for the environmental remediation. J. Hazard. Mater. 146, 617-623. 
Jiang, J.-Q., Lloyd, B., 2002. Progress in the development and use of ferrate(VI) salt as an oxidant and coagulant for water and wastewater treatment. Water Res. 36, 1397-408.

Jiang, J.-Q., Panagoulopoulos, A., Bauer, M., Pearce, P., 2006. The application of potassium ferrate for sewage treatment. J. Environ. Manage. 79, 215-220.

Kjeldsen, P., Barlaz, M., Rooker, A., 2002. Present and long-term composition of MSW landfill leachate: a review. Crit. Rev. ... 32, 297-336.

Kurniawan, T.A., Lo, W.-H., Chan, G.Y.S., 2006. Physico-chemical treatments for removal of recalcitrant contaminants from landfill leachate. J. Hazard. Mater. 129, 80-100.

Lee, Y., Zimmermann, S.G., Kieu, A.T., Von Gunten, U., 2009. Ferrate (Fe(VI)) application for Municipal wastewater treatment: a novel process for simultaneous micropollutant oxidation and phosphate removal. Environ. Sci. Technol. 43, 3831-8.

Li, W., Hua, T., Zhou, Q., Zhang, S., Li, F., 2010. Treatment of stabilized landfill leachate by the combined process of coagulation/flocculation and powder activated carbon adsorption. Desalination 264, 56-62.

Marañón, E., Castrillón, L., Fernández-Nava, Y., Fernández-Méndez, A., Fernández-Sánchez, A., 2008. Coagulation-flocculation as a pretreatment process at a landfill leachate nitrification-denitrification plant. J. Hazard. Mater. 156, 538-544.

McGinley, C.M., McGinley, M.A., McGinley, D.L., 2000. Odor Basics, understanding and using odor testing, in: Inc., S.C.S. (Ed.), The 22nd Annual Hawaii .... McGinley Associates, P.A., Honolulu, Hawaii, p. 16.

Mollah, M.Y., Schennach, R., Parga, J.R., Cocke, D.L., 2001. Electrocoagulation (EC)--science and applications. J. Hazard. Mater. 84, 29-41.

Mollah, M.Y.A., Morkovsky, P., Gomes, J.A.G., Kesmez, M., Parga, J., Cocke, D.L., 2004. Fundamentals, present and future perspectives of electrocoagulation. J. Hazard. Mater. 114, 199-210.

Nicell, J., 2009. Assessment and regulation of odour impacts. Atmos. Environ. 43, 196-206.

Renou, S., Givaudan, J.G., Poulain, S., Dirassouyan, F., Moulin, P., 2008. Landfill leachate treatment: Review and opportunity. J. Hazard. Mater. 150, 468-493.

Sawyer, C.N., McCarty, P.L., Parkin, G.F., 1994. Chemistry for Environmental Engineering, 4th ed. McGraw-Hill, USA.

Skaggs, B.K., 2012. Utilization of Ferrate as a disinfection technology for wastewater reuse. Tulane University.

St. Croix Sensory Inc., 2008. The Nasal Ranger Field Olfactometer Operation Manual. 
Tatsi, A., Zouboulis, A., Matis, K., Samaras, P., 2003. Coagulation-flocculation pretreatment of sanitary landfill leachates. Chemosphere 53, 737-744.

Tchobanoglous, G., Burton, F., Stensel, D. (Eds.), 2004. Wastewater Engineering, Treatment and Reuse, Fourth. ed. McGraw-Hill, New York.

Tiwari, D., Yang, J.-K., Lee, S.-M., 2005. Aplications of Ferrate (VI) in the treatment of wastewaters. Environ. Eng. Res. 10, 269-282.

Trebouet, D., Schlumpf, J.P., Jaouen, P., Quemeneur, F., 2001. Stabilized landfill leachate treatment by combined physicochemical-nanofiltration processes. Water Res. 35, 29352942.

Veli, S., Öztürk, T., Dimoglo, A., 2008. Treatment of municipal solid wastes leachate by means of chemical-and electro-coagulation. Sep. Purif. Technol. 61, 82-88.

Wiszniowski, J., Robert, D., Surmacz-Gorska, J., Miksch, K., Weber, J. V., 2006. Landfill leachate treatment methods: A review. Environ. Chem. Lett. 4, 51-61.

Yilmaz, T., Apaydin, S., Berktay, A., 2010. Coagulation-Flocculation and Air Stripping as a Pretreatment of Young Landfill Leachate. Open Environ. Eng. J. 3, 42-48. 


\section{APENDIX A. SODIUM FERRATE SYNTHESIS}

The synthesis of sodium ferrate followed the procedure presented by Skaggs (2012) and the conversations with Dr. Robert S. Reimers from Tulane University. Due to unstable characteristics of ferrate, a new batch was prepared daily and kept at $4{ }^{\circ} \mathrm{C}$ until use on the same day. Part of this process follows the patented procedure by Ferrate Treatment Technologies, LLC. US Patent number 6,790,429. The amount of reagents required is presented:

Sodium ferrate stock solution:

- $\quad 98 \% \mathrm{NaOH}$

- $68 \% \mathrm{Ca}(\mathrm{OCl})_{2}$

- Anhydrous $\mathrm{FeCl}_{3}$

○ First addition

- Second addition
$74.6 \mathrm{~g}$

$11.5 \mathrm{~g}$

$10.0 \mathrm{~g}$

$2.0 \mathrm{~g}$

Ferrate buffer:

- Sodium Tetraborate Decahydrate

- Sodium Phosphate dibasic
$0.3814 \mathrm{~g}$

$0.8000 \mathrm{~g}$

a) The buffer solution consists of the two reagents added to exactly 1 liter of deionized water. This buffer solution is used for preserving the stock solution and for the spectroscopic readings used to estimate the concentration of the solutions.

b) The sodium hydroxide solution is prepared by adding the $74.6 \mathrm{~g}$ of the solute pellets into $146 \mathrm{~g}$ of DI water. The solution is mixed until the pellets dissolve and the temperature drops to $35^{\circ} \mathrm{C}$. 
c) Then the calcium hypochlorite is added and mixed for $60 \mathrm{~min}$. The mixing speed is increased to account for the increase in viscosity. The beaker is covered in parafilm for safety and to minimize the dissolution of atmospheric $\mathrm{CO}_{2}$. The temperature is maintained at $35^{\circ} \mathrm{C}$.

d) Ferric chloride is added in two steps. On the first one, $10.0 \mathrm{~g}$ are mixed during $45 \mathrm{~min}$. After this time, the remaining $2 \mathrm{~g}$ were incorporated and mixed for $15 \mathrm{~min}$.

e) A small sample is taken with a glass pipette to calculate the concentration of the stock solution. Between 0.12 to $0.18 \mathrm{~g}$ of solution (approximately 3 drops) was added to $50 \mathrm{~g}$ of buffer solution and mixed. Using the UV/Visible spectrophotometer, the absorbance at a wavelength of $510 \mathrm{~nm}$ was determined. This value is later used to calculate the ferrate concentration based on the Beer-Lambert law.

f) Finally, the stock solution is diluted to a 1:1 ratio by weight with the buffer solution. This helps preserve the sodium ferrate and lowers the viscosity of the mixture, making dosing easier. As mentioned before, the final solution is sealed with parafilm and kept at $4{ }^{\circ} \mathrm{C}$. 


\section{NASAL RANGER ${ }^{\circledast}$ Field OLFACTOMETER}

\section{TeSt PROCEDURE FLOW CHART}

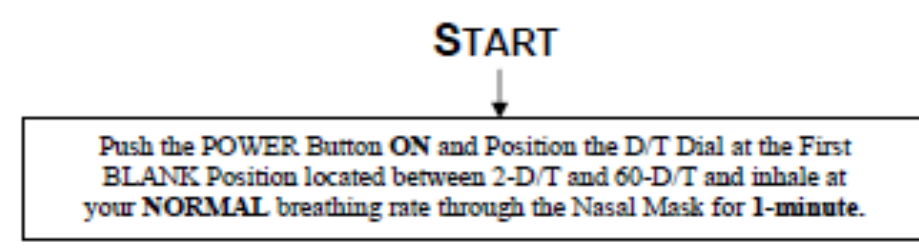

Turn the D/T Dial Clockwise to the 60-D/T Position and inhale TWICE at the Target Inhalation Rate of 16-20LPM through the Nasal Mask.

Turn the D/T Dial to the next BLANK Position and resume your NORMAI breathing rate through the Nasal Mask; and ASK YOURSELF:

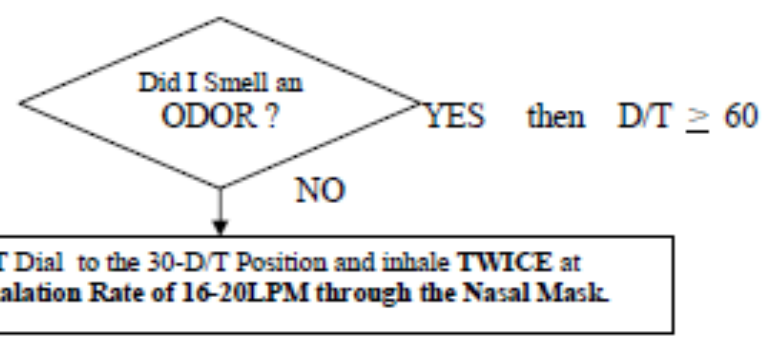

Turn the D/T Dial to the next BL.ANK Position and resume your NORMAL breathing rate through the Nasal Mask; and ASR YOURSELF:

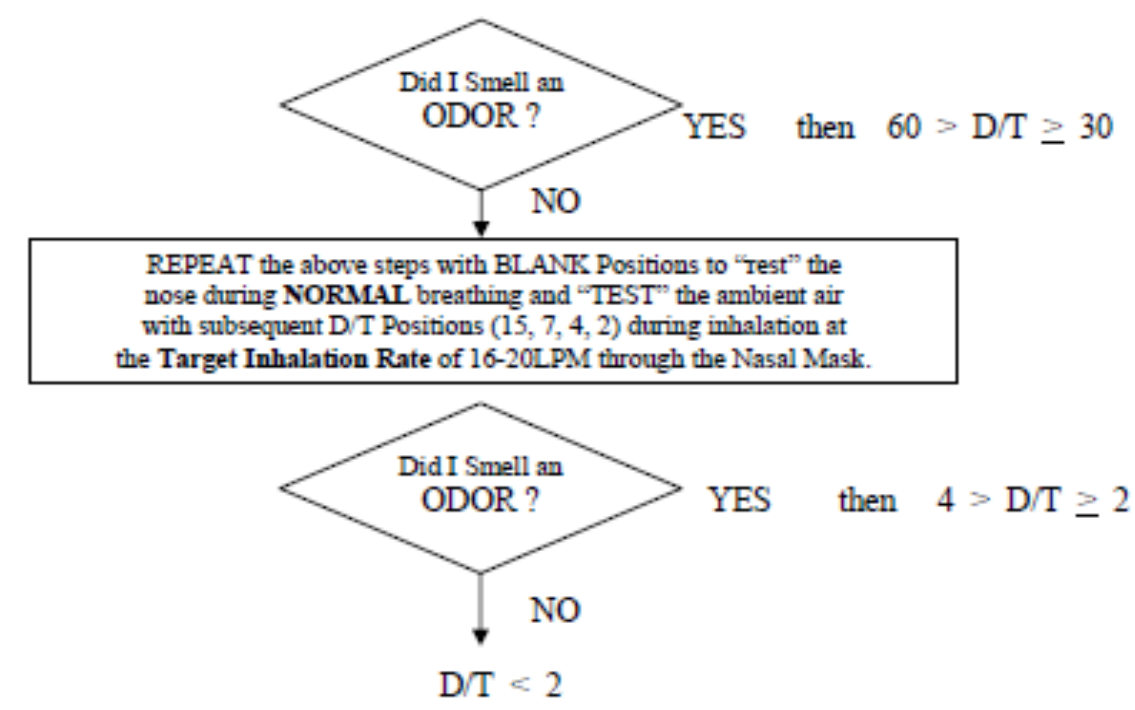

Procedure from The Nasal Ranger Field Olfactometer Operation Manual (St. Croix Sensory Inc., 2008). 